\title{
YOU
}
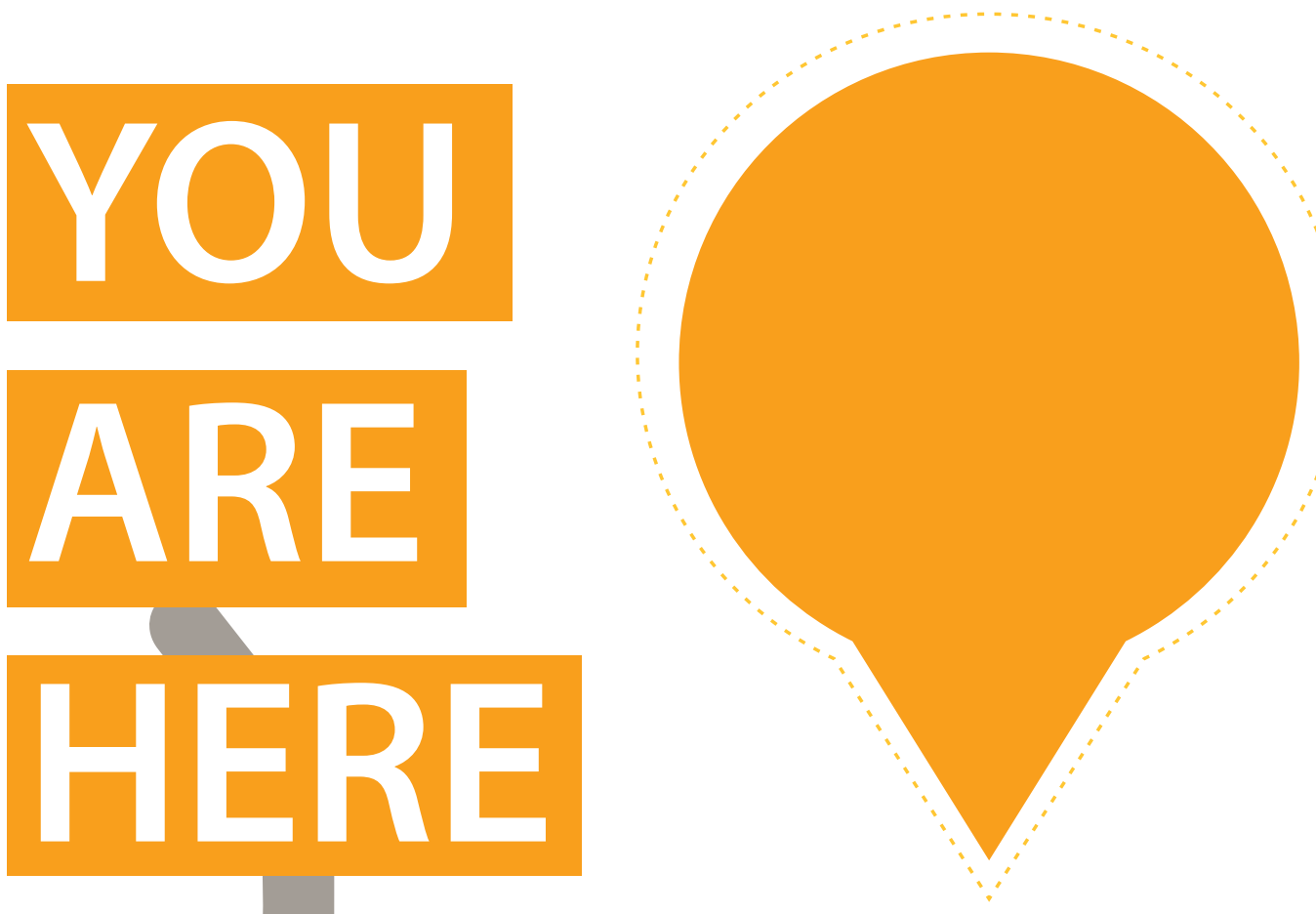

\section{A review of wayfinding strategies for the Toronto Transit Commission}

By Christine Young

Bachelor of Science, McMaster University, 2010

A major research project presented to Ryerson University in partial fulfillment of the requirements for the degree of Master of Planning in the program of Urban Development

Toronto, Ontario, Canada 2017

(c) Christine Young, 2017

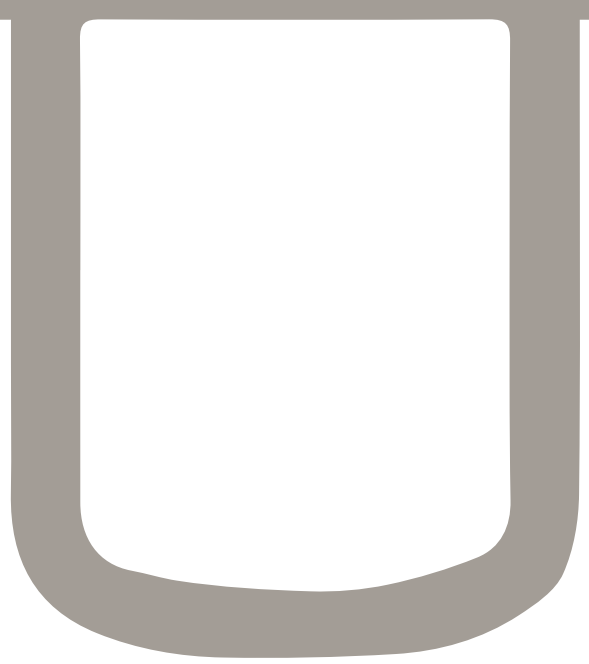




\section{Acknowledgements}

A Major Research Project prepared for the School of Urban and Regional Planning.

Thanks to my supervisor, Professor Nina-Marie Lister

$$
\text { for your support, guidance and direction. }
$$

Thanks to my second reader, Kelsey Blackwell,

$$
\text { for your feedback and direction. }
$$

Finally, thanks to the school for the personal, academic and professional development I gained through the program.

\section{Author's Declaration}

AUTHOR'S DECLARATION FOR ELECTRONIC SUBMISSION OF A MRP

I hereby declare that I am the sole author of this MRP. This

is a true copy of the MRP, including any required final revisions. I authorize Ryerson University to lend this MRP to other institutions or individuals for the purpose of scholarly research.

I further authorize Ryerson University to reproduce this MRP by photocopying or by other means, in total or in part, at the request of other

institutions or individuals for the purpose of scholarly research.

I understand that my MRP may be made electronically available to the public. 


\section{Table of Contents}

\begin{tabular}{ll}
\hline 01 Introduction & 7 \\
\hline 1.1 Lost Underground & 8 \\
1.2 Demand for Wayfinding & 10 \\
1.3 Recent Efforts & 11 \\
1.4 Methods & 12 \\
\hline 02 Literature & 15 \\
\hline 2.1 Growing Trends & 16 \\
2.2 Competition & 18 \\
2.3 Sketching the Blueprint & 20 \\
2.4 New Doors & 22 \\
2.5 Process of Wayfinding for Riders & 24 \\
2.6 Planning and Communication & 26 \\
\hline 03 Wayfinding Strategies & 29 \\
\hline 3.1 Wayfinding Problems & 30 \\
Education Campaign & 32 \\
Information Signs & 34 \\
Station Information & 36 \\
Multiple Languages & 38 \\
\hline 04 Conclusion & 41 \\
\hline 4.1 Implementation Strategies & 42 \\
4.2 Current Conditions & 43 \\
Appendix A & 45 \\
Appendix B & 46 \\
Sources & 47 \\
\hline Strategies & 48 \\
\hline
\end{tabular}




\subsection{Lost Underground}

There are many aspects that demand improvement on Toronto's public transit, but the feeling of being lost underground, which pose a large inconvenience, is in dire need of innovation. This report aims to address wayfinding, attitude, flow and culture without changing the level of service and station architecture (Beirao \& Cabral, 2007).

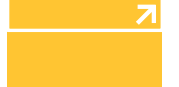 \\ WAYFINDING}

Transit stations are part of an underground system and it can be especially difficult to gain a sense of where you are within the station relative to the outside world. There are many platforms, hallways, underpasses and pathways. Without a wayfinding program it is easy to find yourself taking the long way or even the wrong train. The crowd and the physical environment are major challenges to overcome in the TTC transit stations. It is the first aspect of wayfinding which is done by a traveler navigating a setting.

Thoughtful maps and sign programs help navigate space and fundamentally guide travelers the right direction. Easily read and recognizable signs at points where travelers need them removes the anxiety of traveling (Farr et al., 2014). A wayfinding strategy allows public transit to offer an easy, simple and viable experience. A standard set of signs allows customers to easily recognize, understand and become familiar with the surrounding (Dennis \& Pontille, 2015). This study is centred on developing wayfinding strategies to remove the stress and frustration on public transit, and create efficiency in convoluted stations (Arthur \& Passini, 1992).

\section{ATTITUDE}

Individual attitude regarding public transit ultimately determines mode choice. Those attached to personal vehicles often perceive negative barriers to public transit. Negative attitude often stem from lack of information and observation of service improvements. Observing long queues, for example, at bus stops from inside personal vehicles further feeds this negative perception (Beirão \& Sarsfield, 2007).

It is important to understand customers' perception towards both public transit and private vehicle. With this knowledge transportation planners can target specific service qualities to improve, thus changing the public's attitude regarding public transit. With wayfinding and designs, public transit can improve its image by shifting immediate concerns like bad waiting conditions and lack of information (Beirão \& Sarsfield, 2007; Popuri et al., 2011).

\section{FLOW}

There are a number of physical and mental steps to overcome during the morning and evening rush. Public transit is divided by a series of segments including fare payment, waiting and travel time, entering, transferring and egressing stations (Beirão \& Sarsfield, 2007, Frisken \& Soberman, 2010) In addition, customers have to face crowds of people competing to board trains as well. Before entering riders often have to wait for the crowd of people to exit to finally proceed through bi-directional turnstiles. 'Too crowded' was reported one of the deterring reasons that commuters avoid public transportation (Beirão \& Sarsfield, 2007). Wayfinding during peak times in an already crowded network is one of the main negative attributes of public transportation

This study will examine wayfinding and design strategies that will optimize the circulation and flow on public transit. The current situation has lead to a chaotic movement and circulation on platforms, hallways and concourse. By targeting the flow of people, transit can become a seamless and comfortable experience.

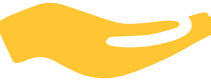

\section{CULTURE}

The culture of public transit comprises of the customers' conduct at stations and across the network including how riders interact with one another.

In 2014, the TTC adopted some strategies to encourage good conduct across the network. Travelers see signs and hear announcements to promote or prevent certain activities. Blue seats, for example, on buses, streetcars and subways indicate priority seating for customers with disabilities, the elderly, or pregnant women. Customers also hear automated announcements that encourage customers to 'stay clear of the doors.' Despite these efforts, old messages have become indistinct amid the disarray of public transit, thus signs are often ignored or have lost their effect. Transportation agencies across different cities have launched education campaigns to develop a friendly culture on public transit and remind customers of good manners. 


\subsection{Demand for Wayfinding}

November 2014 at a town hall meeting, a number of attendees complained about the transit's signs and customer information. Customers found signs were difficult to understand as new signs evolved over the course of the TTC's lifetime. Users requested the "Stand right, walk left" signs around the escalators to be put back in place. In response, the TTC initiated projects that would address design and wayfinding in the city's public transit (TTC, 2013).

The city's transit network requires investment to compete with alternate modes of transportation. Improving design and wayfinding is a moderate intervention that can make public transit more attractive and modern. This study reiterates the need for effective wayfinding and recommends strategies that could create a more comfortable and reliable experience for TTC riders.

This report is divided between a literature, recommendation and an analysis section. The literature reveals the demand for wayfinding in different types of space, and the importance to maintain competition with private vehicles. The solution component reveals strategies that the TTC could adopt to improve experience on public transit. The report concludes with an analysis of the TTC's progress in achieving its wayfinding goals.

In all, the report is centred on graphic communication solutions. Attitude, wayfinding, flow and culture on public transit could be addressed with clean and standard wayfinding signs. New programs would improve aesthetics inside stations and enhance public transit's overall image and navigation. In addition, designs and wayfinding programs introduce solutions that elevates public transit without changing the level of service and station architecture (Beirao \& Cabral, 2007).

\section{Dundas Station}

\section{EXXII}

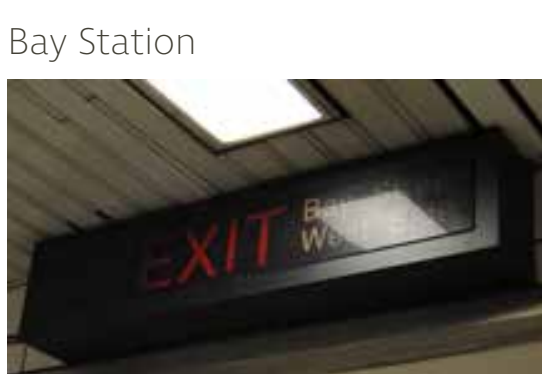

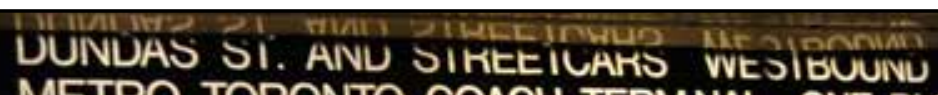
METRO TORONTO COACH TERMNAL ONE BLOCK WEST RYERSON ONE BLOCK EAST
1.3 Recent Efforts

In the last few years, the TTC introduced a number of programs to improve transit experience and satisfaction. The TTC established a five-year Corporate Plan which outlines a vision until the year end of 2017. The strategic plan aims to address the system from customer satisfaction, affordable expansion to asset management (TTC, 2013). Since 2015, the TTC achieved a number of those targets to increase customer information and ease movement across the network. New features include (TTC 2015 TTC; 2016)

- New fare gates at St. Clair, Summerhill and Main Street Station

- Installing new customer information screens

- Accepting PRESTO fare payments

- Plans to replace stop markers at over 3000 transit stops

- Increasing special constable's responsibility to manage traffic

In addition, the TTC implemented signs across public transit to improve wayfinding and planning trips (TTC, 2013). The TTC completely updated its design manual,but looking closely, old signs are everywhere in a number of stations. Toronto's transit is suffering from old infrastructure and limited space, and the city is struggling to find new financial sources. The pipeline has hefty investment plans for Toronto's transportation infrastructure, but Frisken and Soberman (2010) argues that alone will not improve public transit entirely. Service quality is significantly lacking and becoming harder to find new solutions. Service quality should involve customers and employees in the planning process to change the culture surrounding public transit ( Soberman, 2010). In addition rebuilding aging stations would rely on costly renovations and infrastructure. For this reason, this report explores modest solutions that could enhance public transit. 


\subsection{Methods}

A review of secondary sources and a nonreactive qualitative approach is the basis for this study. The research focused on literature and solutions that would improve the overall public transit experience that would not require changes in the overall service and station architecture. This report is two-fold: a literature section discussing the process and need for wayfinding and a solution section including different designs.

Academic and public sources helped inform this study's portfolio of best practice in wayfinding designs. Data were collected from government and transportation agencies to explore wayfinding goals and strategies applied in the industry. A range of design solutions were considered depending on their adaptability within the TTC network. Metro systems were examined based on similar transportation and urban conditions including significant traffic pressure and population growth. In all, the report involves secondary research that explain wayfinding and support the need for an effective map and sign program.
Conclusions were also drawn from field observations and analysis with research methods rooted in William Neuman (2006)

and design principles by Paul Arthur and Romedi Passini (1992). Neuman's guide in active and complete participation in the field allowed a greater understanding of the customer's experience. Assuming different roles, such as a child or an elderly, supplemented the findings and revealed different challenges of wayfinding on public transit.

Gibson (2009) states methods in wayfinding is based on understanding the patterns of a setting and uncovering the 'hidden logic'.

"The hidden logic is the pattern of movement or spatial organization that characterizes a place and serves as a framework for the wayfinding system." Gibson, 2009, p.44)
With this principle in mind during site observations, various wayfinding factors were examined using Neuman's approaches in field research.

- Different environments (i.e. fare concourse, subway platform, entrances, exits, corridors)

- Physical characteristic and circulation patterns

- Points of view of different riders

- Overlaps, parallels and contradictions in signs

- People's experience or expected experience of a place

- The process of wayfinding

(Gibson, 2009:Neuman, 2006)

These basic aspects of wayfinding design guided the site research. Gaining perspective on the riders experience was the primary objective during observations.
The observed stations were situated on the yellow and green line and south of Bloor These locations were chosen because they experience high volume, aging infrastructure and limited space which demand wayfinding solutions. Notes, diagrams and pictures were documented during two periods, February 9th and 10th 2017, between 10.00 AM and 3:00 PM. Unfortunately, these were the only times permitted by the TTC to take photographs and observations. A property permit was required to access platform and concourse areas on TTC property (Appendix A) and a certificate of insurance from Ryerson University (Appendix B)

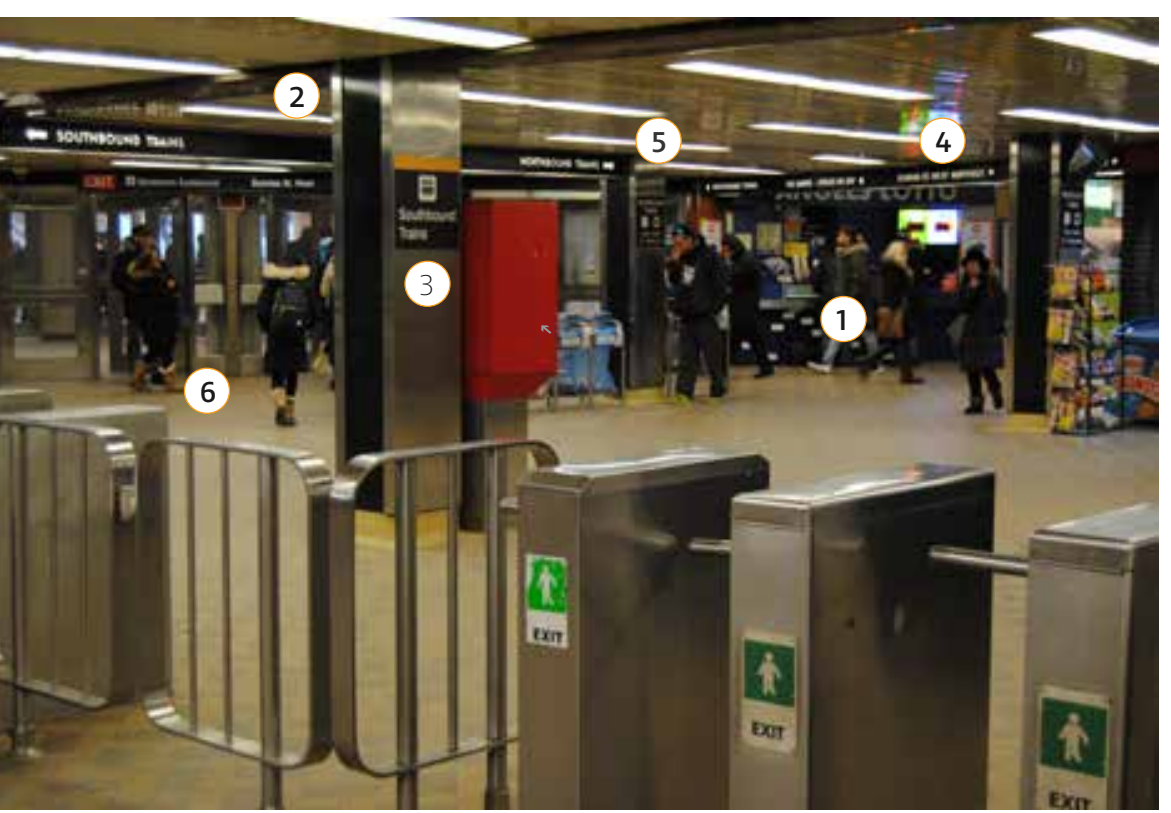

Elements considered during ste observations:

1 Density

2 Height

(3) Location of sign

(4) Visibility

(5) Legibility

6 Physical environment 


\section{2}

\section{Literature}

Literature explored reveals recent trends and growth that demand attention be paid to improving the TTC's wayfinding network. To improve experience on public transit, stations and lines need to be examined separately and as connected system. Investing in the TTC's design and wayfinding strategy will enable public transit to compete with private vehicles. This presents an opportunity to collaborate with other municipal departments and the artistic community.

In order to address challenges with wayfinding, attitude, flow and culture on public transit, a basic understanding of wayfinding is a prerequisite. The next sections outline the process of wayfinding for travellers and planners. 


\subsection{Growing Trends}

There has been significant population growth and development across the Greater Toronto and Hamilton Area (GTHA). There is pressing need to invest in public transit with increasing development in downtown Toronto and flow from surrounding regions. In 2006, downtown Toronto was designated as an Urban Growth Centre by the province in the Growth Plan for the Greater Golden Horseshoe. The population today in the GTHA is over 6 million people (Metrolinx, 2008). Projections expect the population to grow up to 8.6 million people by 2031 (Metrolinx, 2008). The following pulses are putting pressure on the state of the TTC system (Ostler, 2014):

\section{Population}

Between 2016 and 2041, downtown Toronto's population is projected to grow 1.9 times the current population (City of Toronto, 2016)

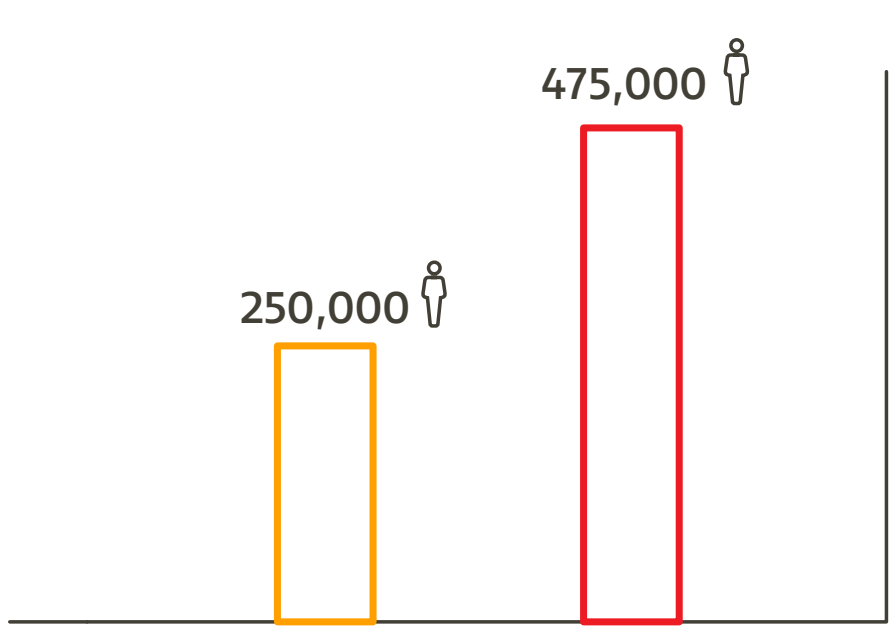

2016
2041
Development

Development in downtown Toronto is growing as well. Between 2008 and 2013 , the following proposals were submitted to to the city (Ostler, 2014):

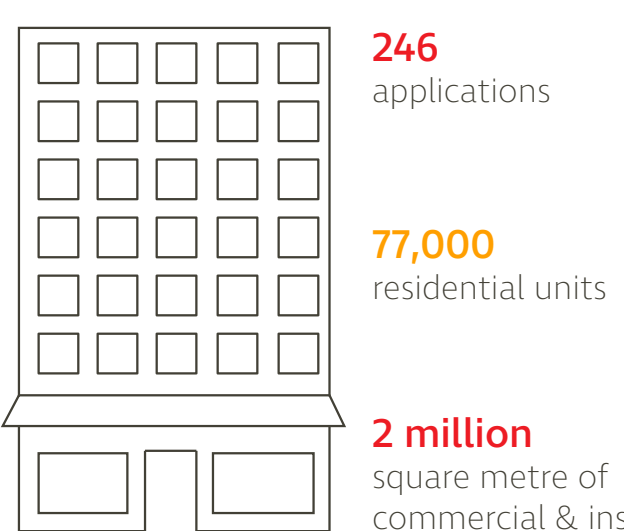

Age Cohort

There has been a shift in downtown's demographics. For several years, baby boomers exceeded the number of echo boomers in the city's Downtown. However, in 2011, the city's downtown saw a switch in the dominant age group. Echo boomers represent over $43 \%$ while baby boomers account for about $23 \%$ of the population (Ostler, 2014).
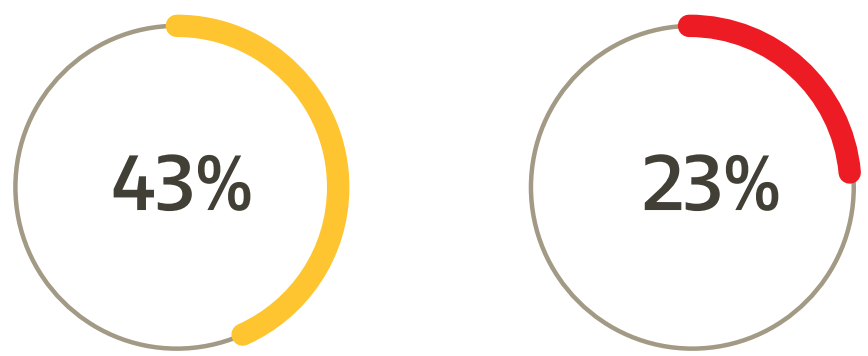

Echo boomers

Baby boomers
Jobs

446,000 jobs were reported in the

Downtown core in 2012 Toronto's largest employment area. Studies also reported that job growth could increase from 5\% to $21 \%$ by the year end of 2031 (Ostler, 2014).

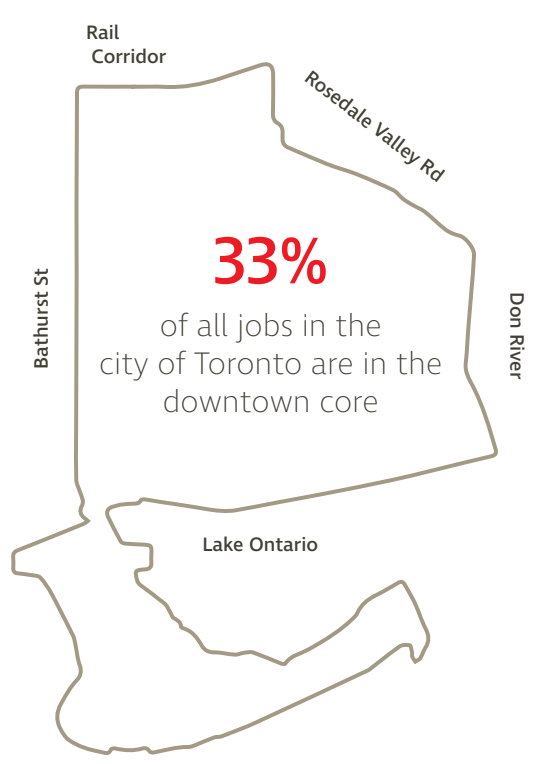

Trip Origins

There is movement from every direction for jobs downtown. The origin of trips range from Downtown to outside the GTHA (Ostler, 2014):

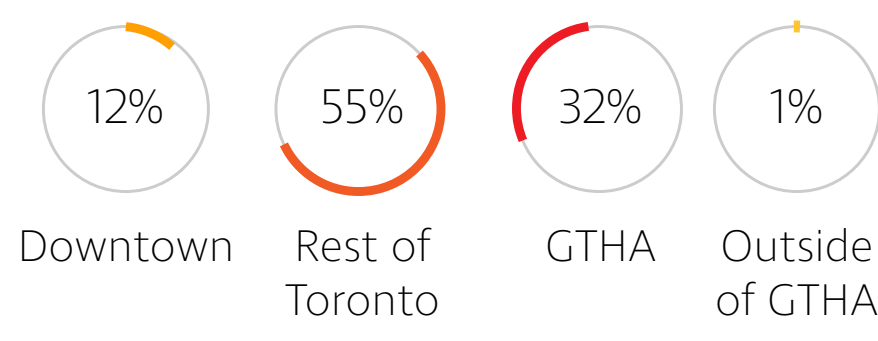

Those traveling downtown commute by vehicle, transit and walk or cycle.

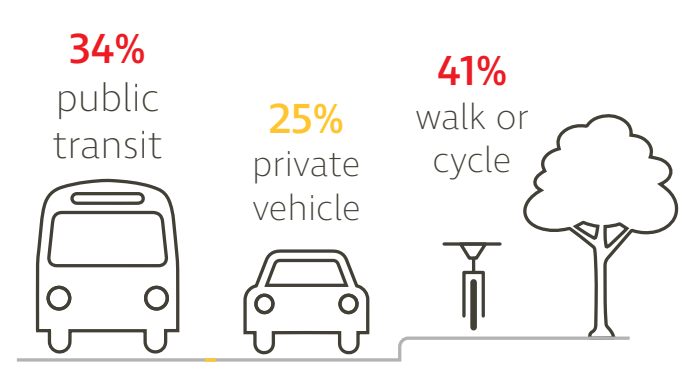

Why Downtowi

People chose downtown because:

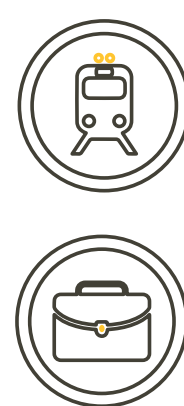
Access to transit Close to work
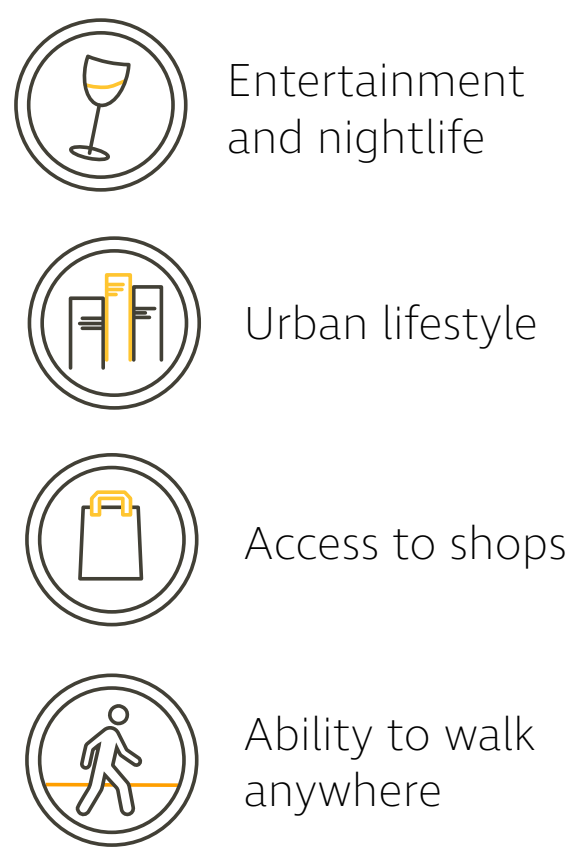

(Ostler, 2014) 


\subsection{Competition}

Public transit is being pushed by increasing growth, but also pulled by the preference for private vehicles. Vehicles maintain a competitive edge as they offers direct service. Private vehicles offer comfort, speed, convenience and individual freedom and as a result maintain attractiveness (Beirao \& Cabral 2007: Frisken \& Soberman, 2010). The number of trips by private vehicle in the GTA increased by 56\% between 1986 and 2006 (Metrolinx, 2008). Public transit, unfortunately, does not offer the same door-to-door route as private vehicles.

commutes on public transit are comprised of fare payment, waiting and travel time, entering, transferring and exiting stations. Commuters need to carefully plan their trips before taking transit, and not to mention seats are not guaranteed (Guo, 2011).
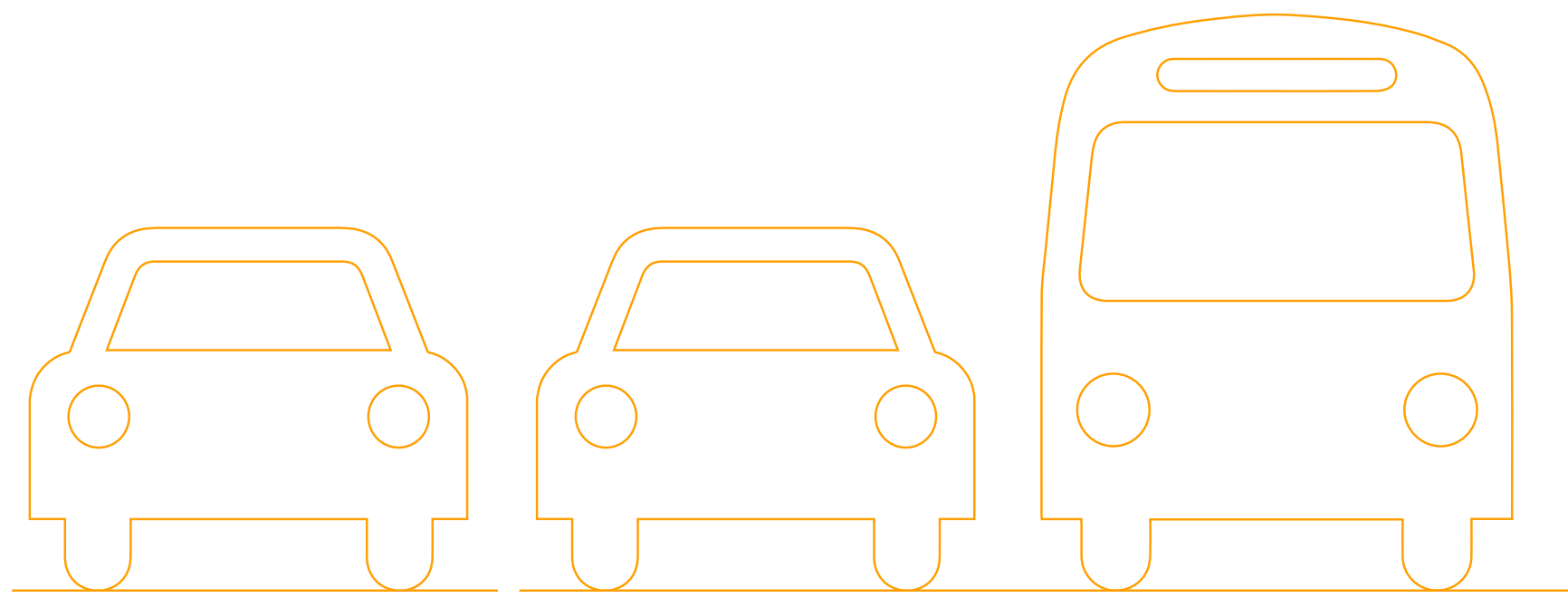

All major transit systems require commuters to transfer at least once. Transfers are a fundamental part of commuter's travel experience but are often overlooked (Guo \& Wilson, 2011). Public transit is at significant disadvantage as transfers divide routes and prevent commuters to sit back and relax.

In order to compete with private vehicles services need to deliver an attractive and a friendly environment (Kepaptsoglou, et. al., 2013). Public transit needs to promote its image in order to become competitive and gain more riders (Beirao \& Cabral, 2007). When considering locations where customers must transfer, planners need to consider each segment from walking, waiting and the physical environment that connect different lines. Each

fragment requires unique solutions and implementation strategies (Guo \& Wilson, 2011).

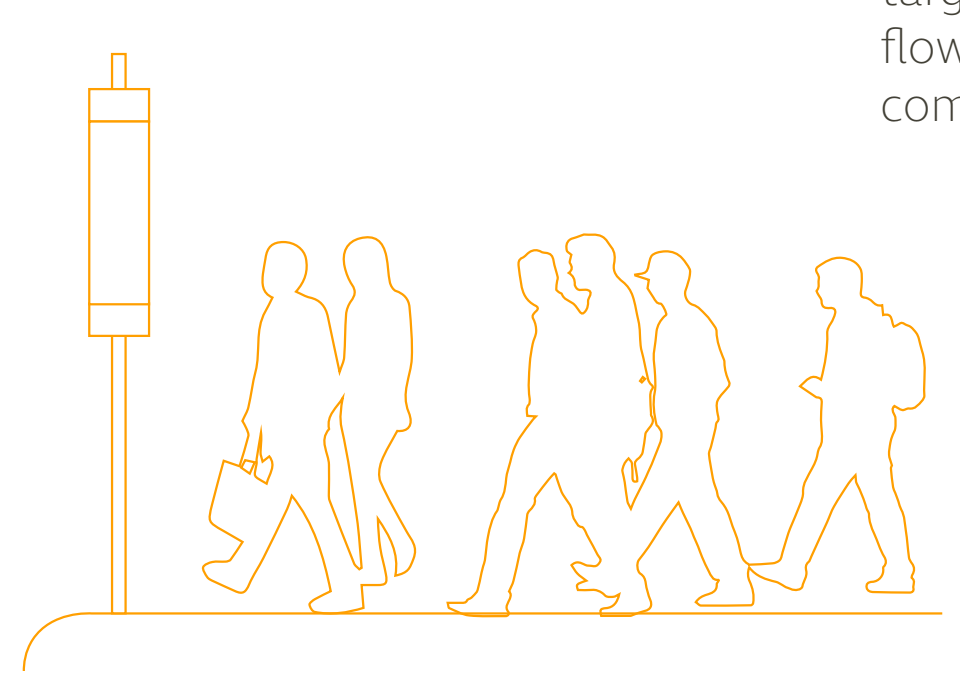

In all, a good pedestrian environment can promote public transit and discourage vehicle use (Guo, 2009). Effective

wayfinding and signs have been argued to facilitate flow and movement of people. Standard colours, typeface and size creates a seamless wayfinding system that commuters can easily recognize and navigate. Consistent symbols, colour and language allows user to feel familiar and greater comfort while travelling by public transit (Denis \& Pontille, 2015). Creative design and wayfinding solutions could also help traffic and rider's stress within Toronto's congested system. Transfers is a large weakness of public transit, so centering service planning at connection points would allow public transit to better compete with private vehicles. Effective design and wayfinding could eliminate the inconvenience where customers need to transfer, and make a more attractive environment. In all, design solution could target altogether, wayfinding, attitude, flow and culture providing a more comfortable and enjoyable transit. 


\subsection{Sketching the Blueprint}

Before planning for design and wayfinding strategies, it is essential to understand the units that encompass public transit. Lines and nodes are the basic types of space that need to be considered in planning for transit (Rüetschi \& Timpf, 2005). The network of bus, streetcar and train routes are the lines whiles nodes are connection areas between different lines. Together the nodes and lines sketch the blueprint for public transit.

Walking, waiting, traveling, information availability, accessibility to information and overall ease of transfer are steps that contribute to the connectivity at nodes. Yudal and Ranjitkar (2012) describe that connections between lines should be a seamless and synchronized experience that allow riders to reach a destination effortlessly.
Network information, including times and maps, is readily available on transit website or at service areas. However, information about connection areas is less accessible. The process of wayfinding within station relies on searching, following, exploring and matching information in a complicated setting including halls, platforms, underpasses, corridors,

concourse. Therefore, gaining a sense of the layout can be difficult unless already familiar with the space (Rüetschi \& Timpf, 2005: Arthur \& Passini, 1992)

In sum, lines and nodes differ considerably in scale and the rider's ability to navigate a route. Activities on both lines and nodes are an interconnected system, and any delays on the line can impact traffic across stations. A health emergency, as a result, not only slows service on lines, but also creates congestion on platform areas.
That said, lines and nodes need to be

examined separately and together to plan for public transit (Rüetschi \& Timpf, 2005). These issues on transit will not resolve themselves, and so important to provide the means,

wayfinding, to create a effortless experience. Whether improving wayfinding or availability of service information, these tools must be used to improve the entire blueprint of public transit.

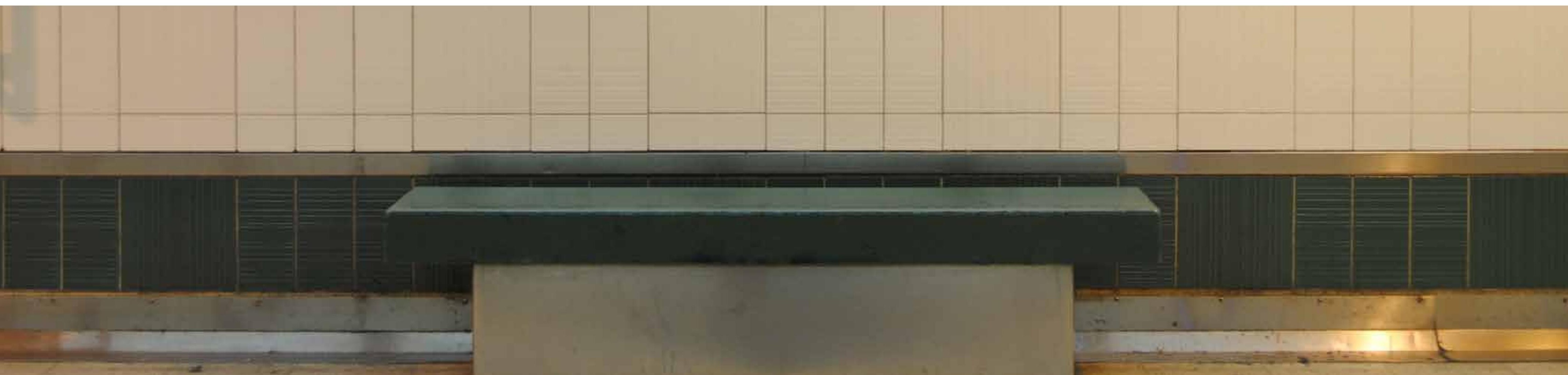




\subsection{New Doors}

\section{Local Strategies}

Design solutions to address attitude and overall transit also opens new doors for the TTC. Adding art and creative work within public transit allows the commute to become more enjoyable, and transforms a regular path into an interesting place of its own. This presents the TTC the opportunity to work with other city departments and organizations to collaborate on design and sign solutions.

In the last year, the TTC introduced a number of programs to create a more enjoyable and interesting experience for Toronto commuters:

- November 2016, the TTC worked with the famous, landmark retail store, Honest Ed's. The TTC decorated Bathurst station with the store's iconic bright red, yellow and blue discount signs.

- We Move You posters and videos were released across the network. The campaign was a collaboration between the TTC and the National Ballet of Canada. Nine dancers were photographed dancing on the TTC's new streetcar and subway and at Union station.

- The Art for Commuters is a another

collaboration between the TTC and artists. A number of programs and artists are called upon to showcase local art and culture along the TTC platform. 'Sketching the Line" was

the most recent poster program on platforms and trains.

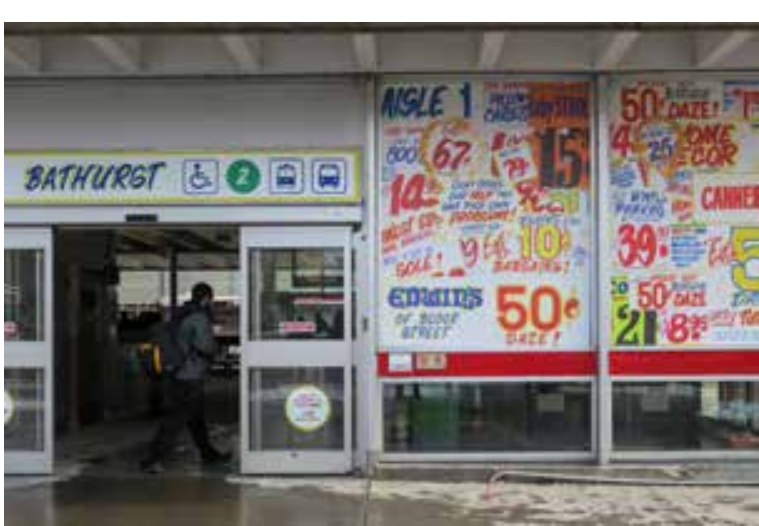

Bathurst Station transformation in tribute to the famous Honest Ed's (Reeve, 2017)

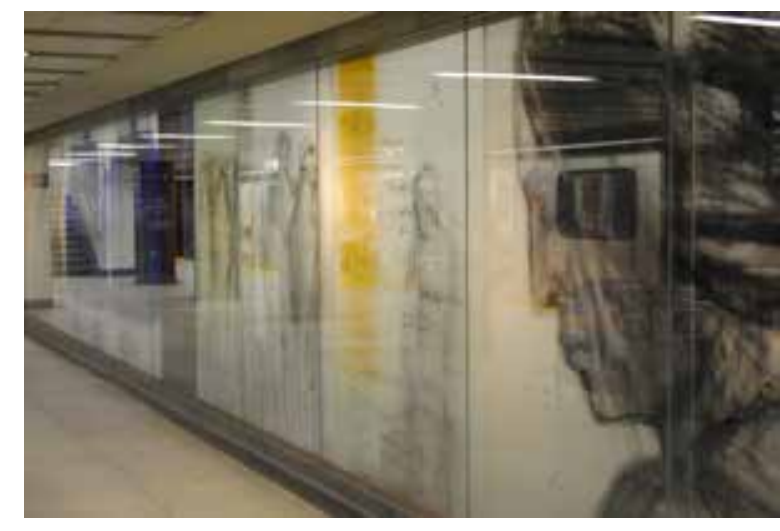

Zones of Immersion art installation by Stuart Reid at Union Station.

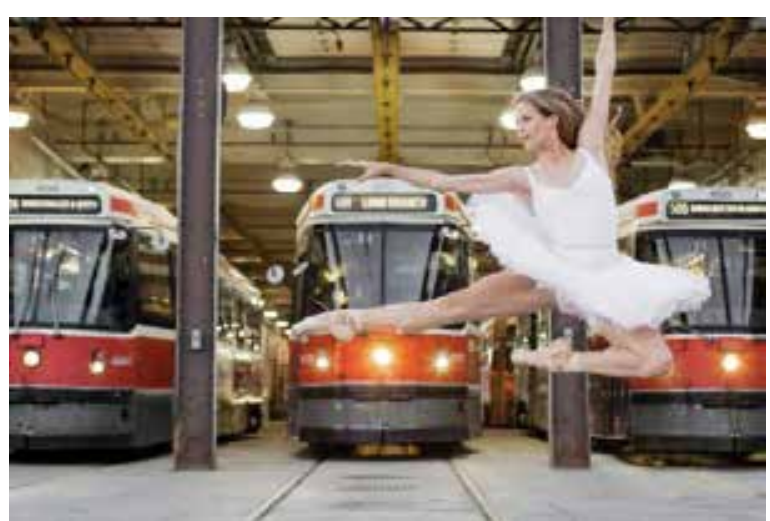

Photograph of the TTC's and the National Ballet's We Move You campaign (NBC,2017)
Comparator Cities

Other cities have also collaborated with different program to share art and culture within their transit system (Zerdoun, 2016). Public art on transit adds immeasurable value and has a two-fold effect: it add life and character when the art work includes elements of the community. This strategy also helps wayfinding by identifying a path or a node with unique and innovative artwork. Some examples include:

- Chicago Transit Authority (CTA) transformed many pathways, platforms, stations into beautiful places. Chicago's portfolio includes Francisco Station where ordinary pathway was converted into an oriental rug to express the community's culture diversity.

- New York's Metropolitan Transit Authority also has an established art and design department to enhance transit experience. since the 1980's, MTA uncovered over 300 art work including the Tranquility design - twelve panels of stained glass, at Mount Vernon East Station.

- Universidad de Chile in Santiago installed a floor-to-ceiling mural by Mario Toral. It is titled Memoria Visual de una Nacion and it represents the history of Chile from the Spanish conquest to today (Zerdoun, 2016).

The success of collaborating with local community and artist in other cities demonstrate the ability for the TTC to realize the same. Ordinary spaces can be transfomed into beautiful places making public transit an interesting and enjoyable experience rather than just a mean of transportation.

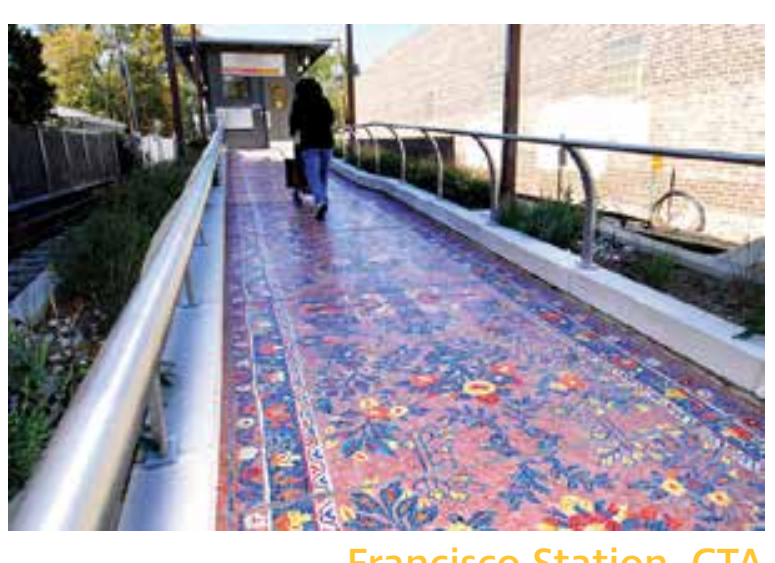

Francisco Station, CTA

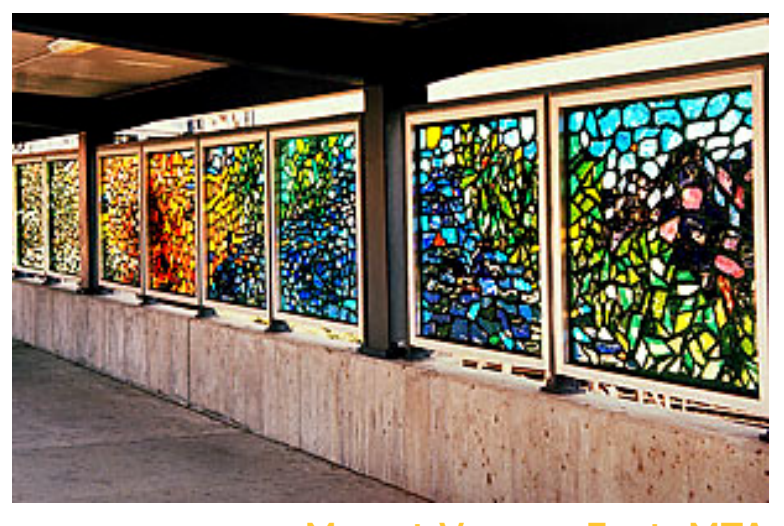

Mount Vernon East, MTA

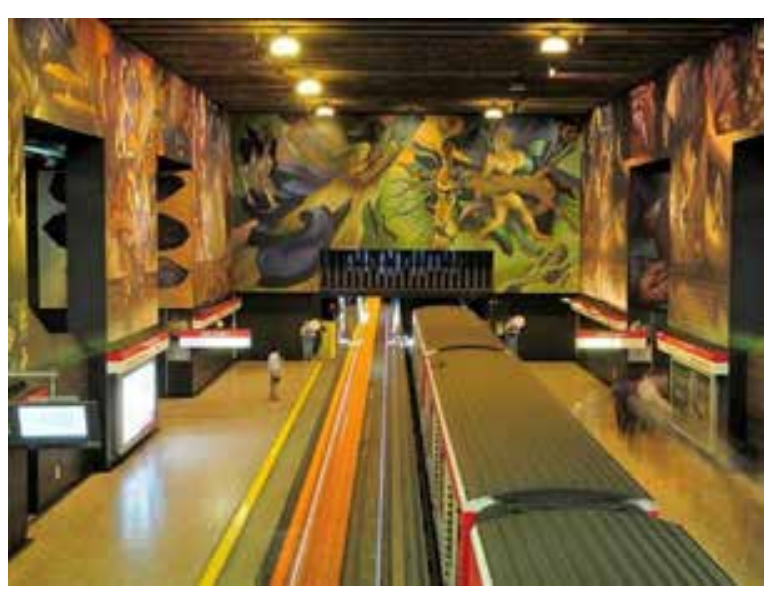

Universidad Chile, Santiago Metro 


\subsection{Process of Wayfinding for Riders}

Studies generally (Arthur \& Passini, 1992; Denis \& Pontille, 2015; Farr et al., 2014: Gibson, 2009; Guo, 2009; Guo, 2011; Guo \& Wilson, 2011; Li et al., 2012) agree maps play an important role in communicating spatial information. To implement new design and wayfinding strategies, understanding the steps of wayfinding, importance and impacts of maps and information included is a prerequisite. The following elements explore the process of wayfinding for travelers on public transit, to gain perspective of the commuter's experience.

\section{STEPS IN WAYFINDING}

Farr et. al. (2013) focused on the process of wayfinding in airports. The authors divided wayfinding into four steps namely orientation, route selection, route control and destination recognition. These steps require a person's cognitive mapping skills to navigate through human factors (i.e. spatial orientation, language, culture, gender, biology) and environmental factors (i.e. paths, nodes, landmarks, layout complexity, signs).

\section{INFORMATION}

Maps deliver four type of information including distortion, restoration,

codification and cognition (Guo, 2011). Distorted information is simplified information to create a schematic map of transit lines. Restoration aims to include geographic features like roads and parks to help connect the rest of the city to transit lines. Codification represents important locations through symbols and colour. Finally, cognition is the perception users interpret form a transit map that helps understand the spatial context.

\section{1| Front entrance}

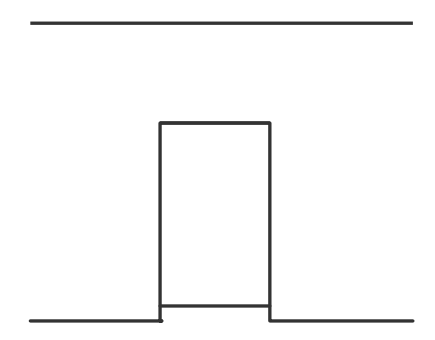

Some entrances are clear and do not require wayfinding The third entrance, however, is hidden and requires a sign to indicate right direction (Arthur \& Passini, 1992).

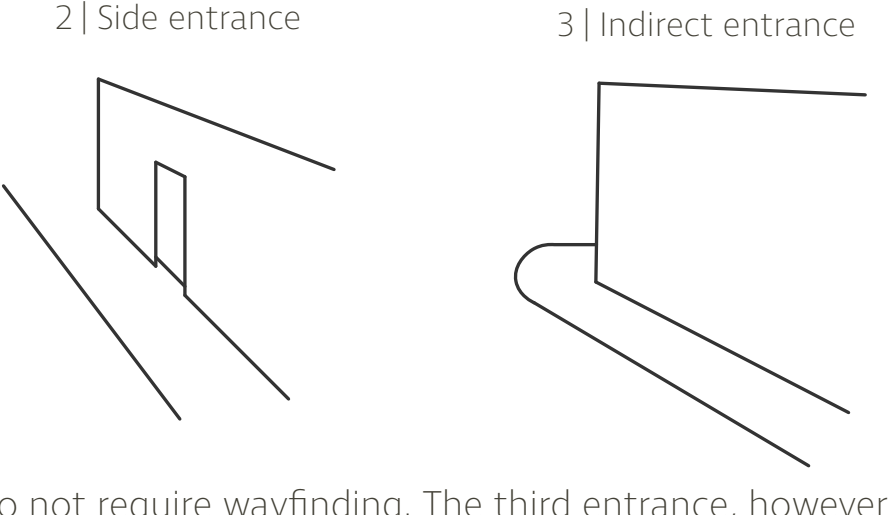

In all, maps could be a planning tool to create efficiency within public transit networks (Guo, 2011). Scaling and symbols in maps can be revisited to minimize crowding on platforms and change travel patterns. Transit maps and signs complement each other and help customers navigate stations and the greater transit network.

\section{IMPORTANCE OF MAPS}

Research findings revealed that human factors have larger influence on wayfinding than environmental factors. Although planners have no control over a person's spatial orientation ability, the authors found environments can be designed to mitigate travel anxiety with clear pathways and quality visual communication (Far et. al., 2013). Guo (2011) also argues that maps have a significant impact on the travel behaviour and path decision. When a path is drawn longer, a passenger will likely choose a shorter path (Guo, 2011). People also prefer routes with the fewest turns, and instead take a linear route despite being longer. Maps are important tool to reduce the anxiety of new and complicated surroundings.

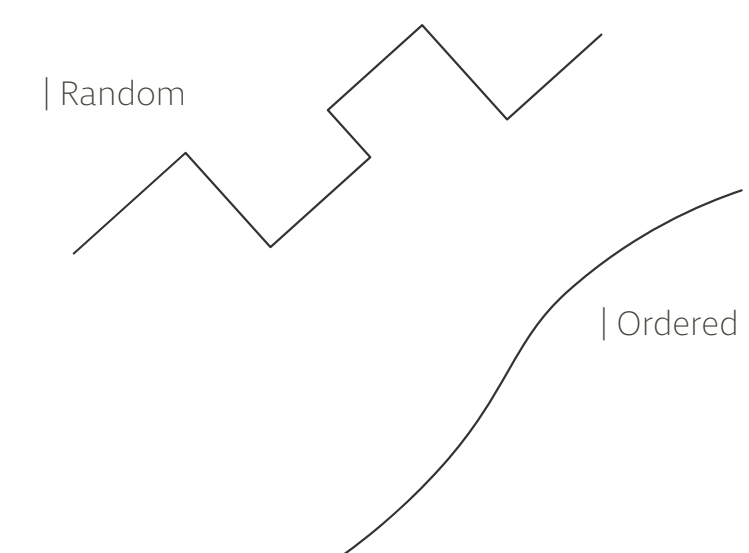

Random paths versus an ordered system (Arthur \& Passini, 1992) are more difficult to navigate and require wayfinding at various points.

\section{IMPACT}

Altogether, the different information provided within maps impact customer's decision on location, mode and path. Guo (2011) found that commuters rely more on maps than personal experience. Schematic maps drawn more or less direct can encourage users to take the apparent easiest path. Incorrect representation could ultimately direct traffic towards congested and overcrowded platforms Guo, 2011). Guo (2011) also found transit maps reduce the use of buses as an alternative option because train are simple and easy to understand while bus maps are usually more complicated to interpret and plan a trip. Denis and Pontille (2015) also argue that signs can control pedestrian movement and create order

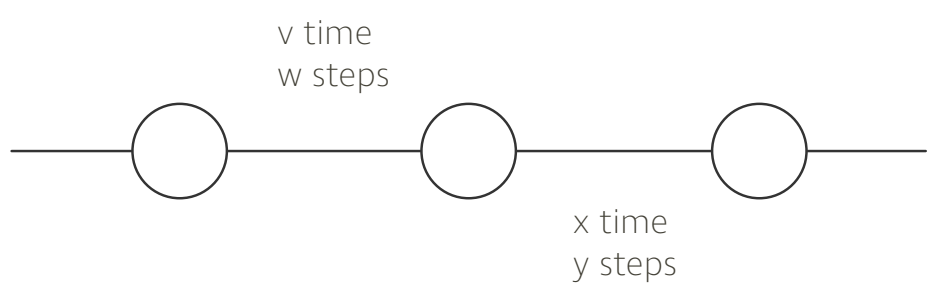

City of London provides walking times and steps between each station to encourage riders to walk during peak hours on public transit. 


\subsection{Planning and Communication}

Wayfinding is the art and science of organizing and communicating spatial information. As previously discussed, wayfinding is the process of navigating and interpreting the layout to reach a person's destination. Using messages and diagrams wayfinding designers aim to provide relevant information at the times when travelers need it. There are two fundamental aspects that frame wayfinding design: spatial planning and environmental communication (Arthur and Passini, 1992)

Spatial planning is the process of uncovering and understanding the organization within a space. The space is characterized by its site, size, content function and circulation patterns.

\section{Steps in spatial planning include:}

- Identifying constituent spatial units

- Grouping similar units into destination zones

- Organizing and linking units and zones (Arthur and Passini, 1992)

Spatial planning identifies the

entrances, the exits, landmarks and major destinations and functions of a place. Understanding the content and organization allows planners to group similar units into destination zones. This approach creates order and simplicity within a large network. Imagine a campus, it is difficult to find a classroom without knowing first which building or department a student needs to be in. The steps of spatial planning aim to help visitors to easily create a mental map of the setting and find where they need to go. (Arthur and Passini, 1992
Environmental communication is the form in which information is conveyed for wayfinding including architectural, audible and graphic expression. This report focuses on the graphic expression for

wayfinding information (Arthur and Passini, 1992). Basic rules of thumb regarding typography, pictographs, colour, layout and other components guide best practice in graphic design but, above all, people's psychological and behavioural patterns lays out the framework for wayfinding. Environmental communication provides the essential information to make and execute decisions along a path and to gain a sense of the layout (Arthur and Passini, 1992).

There are a number of environmental characteristics that also need to be considered for communication. Brightness, density of people and height of ceilings, for example, can all interrupt the ability to navigate a setting. The form in which information is presented is important as well to ensure legibility and readability. People learn to recognize signs and

remember their meaning after having seen it multiple times. This strategy relies on the use of consistent colours, location and structure of information (Arthur and Passini, 1992; Gibson, 2011).

Spatial planning and environmental communication together sets the framework for wayfinding design. Gaining the perspective of a visitor is preeminent and complimentary in developing effective wayfinding strategies. With users at the centre of planning and design, wayfinding can enhance the experience of a place Gibson, 2011) and create a comfortable experience. Creating a seamless experience is the inherent goal for wayfinding design. 


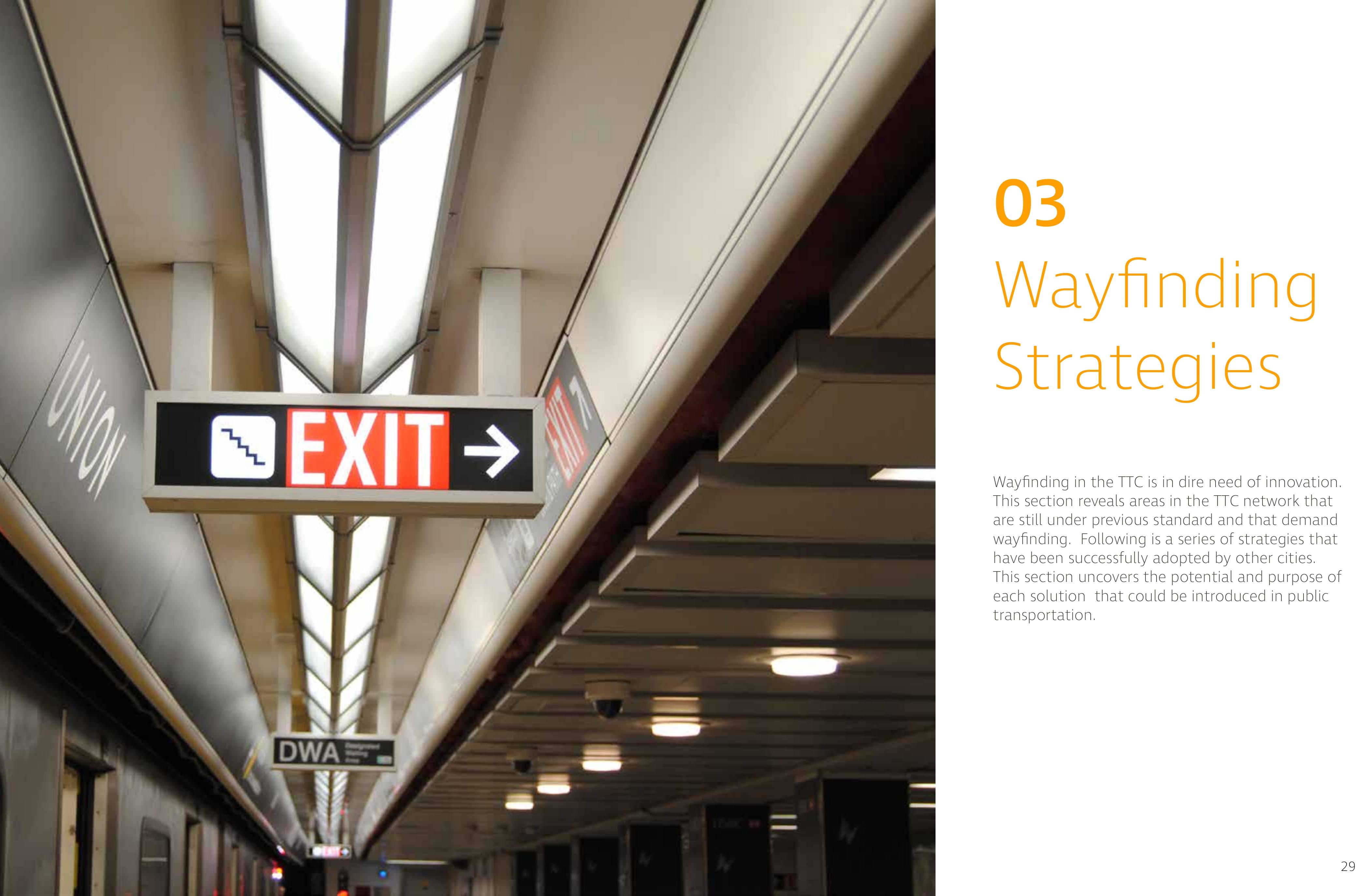




\subsection{Wayfinding Problems}

Bloor Station

Fair Concourse \& Southbound and Northbound platform
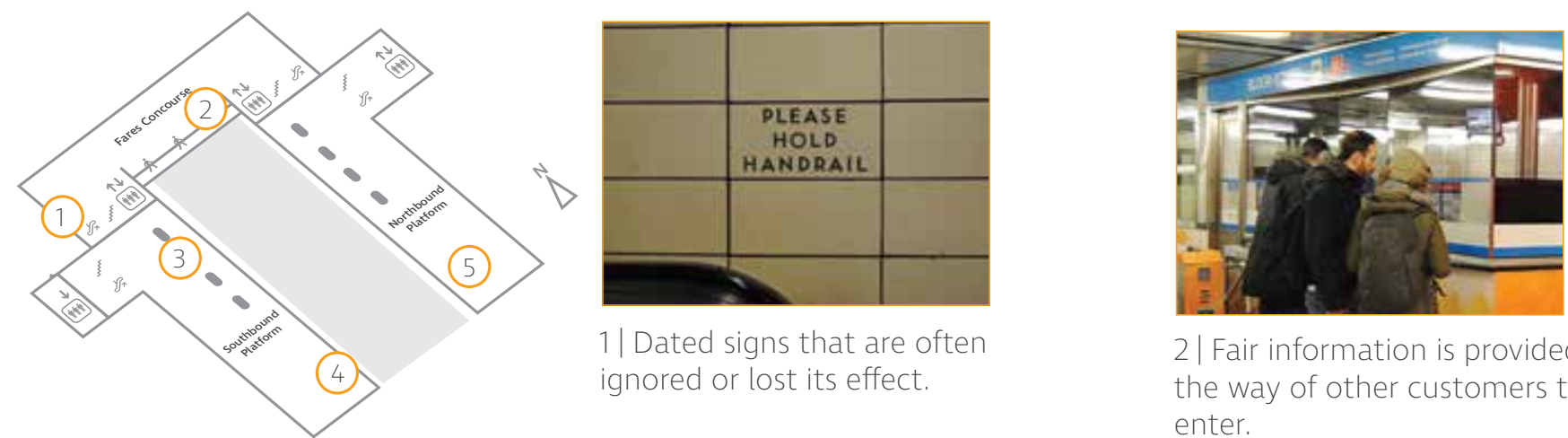

Problem areas at various stations

| Dated signs that are ofter

ignored or lost its effect.
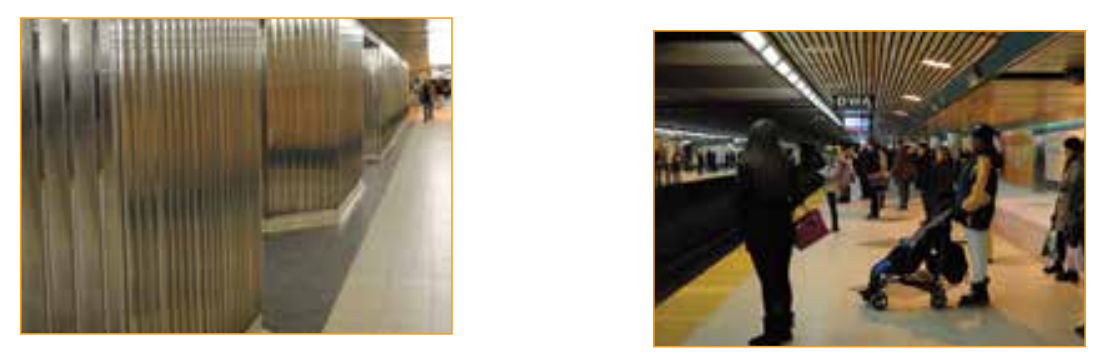

3) Large pillars obstruct

crowded platforms.

\section{Passengers stand disor-}

derly waiting for the next

$2 \mid$ Fair information is provided in
the way of other customers to the way

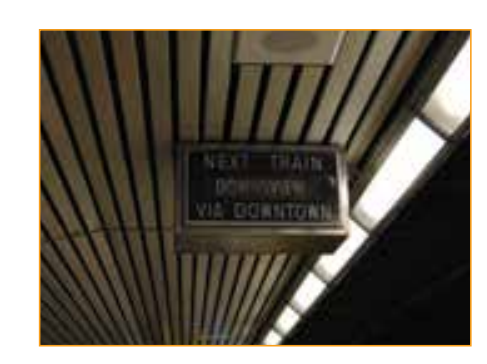

$5 \mid$ Sign is bulky and dated, an
hardly visible from a distance.

Dundas Station

Fair Concourse \& Southbound --platform

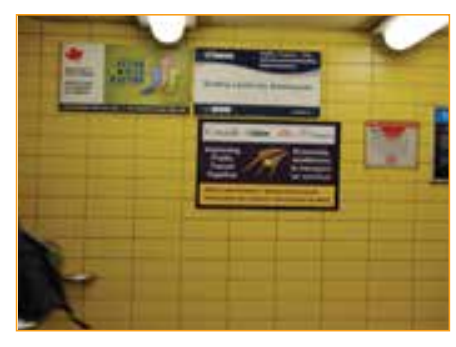

1 | Detailed public information is provided directly
front of a walk way

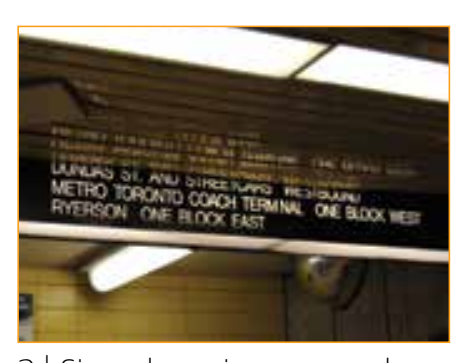

$2 \mid$ signs hanging on angle prevent customers to under
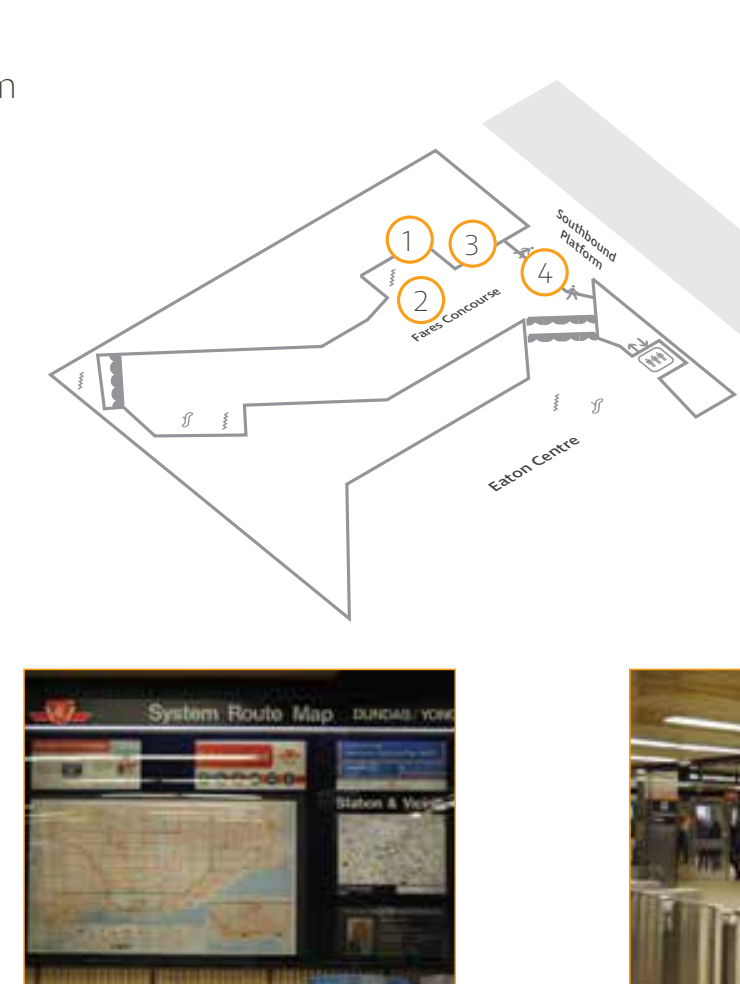

3 | Costumer information is segregated and lacks flow

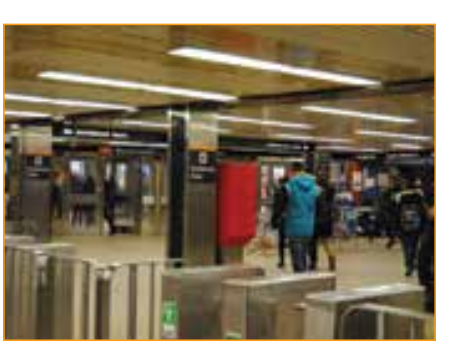

4 | Lack of simple design in a busy station creates a chaotic

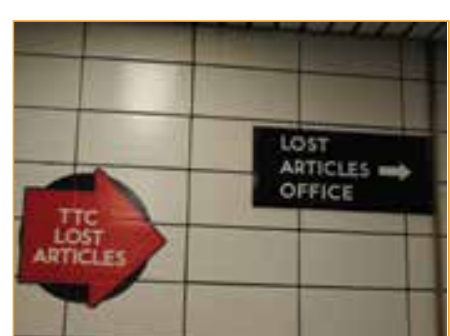

Redundant signs used to

repeat information.

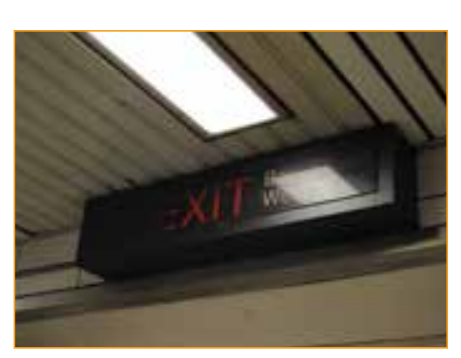

Signs are hardly visible with poorly lit signs.

Bloor
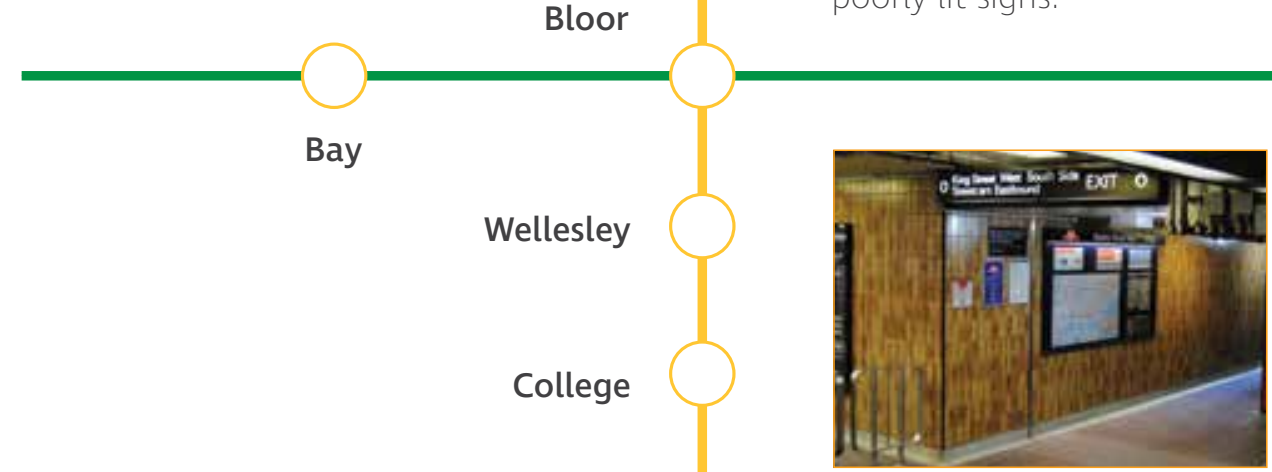

Detailed information and maps are posted directly in

Queen
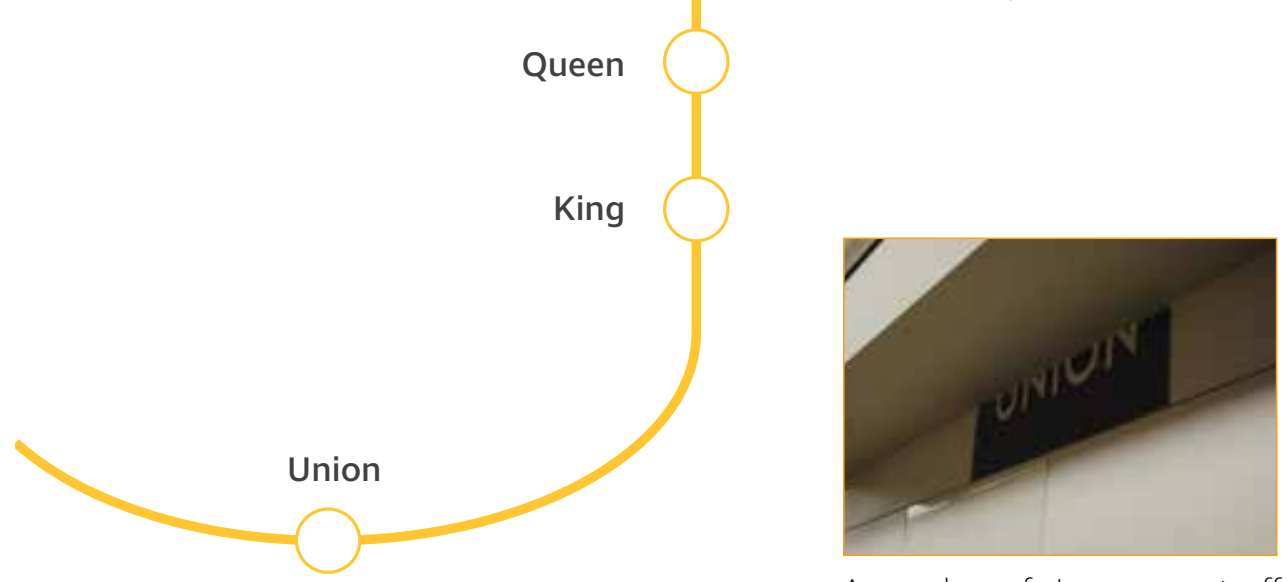

A number of signs are cut off

preventing customers to understand

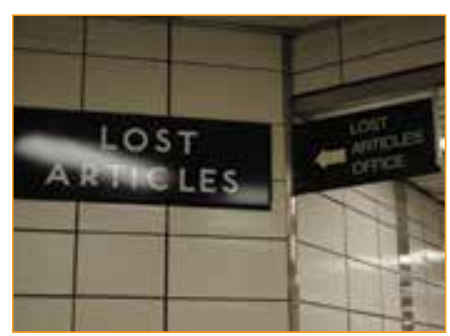

Signs have not all been updated

yet at various locations.

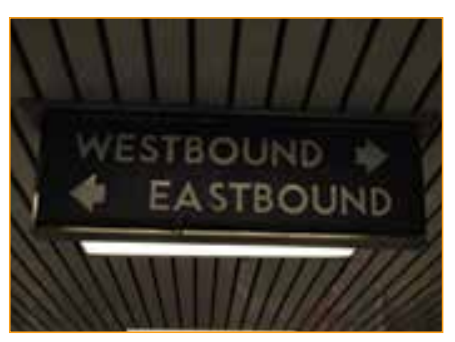

Many signs are still under old wafinding standards.

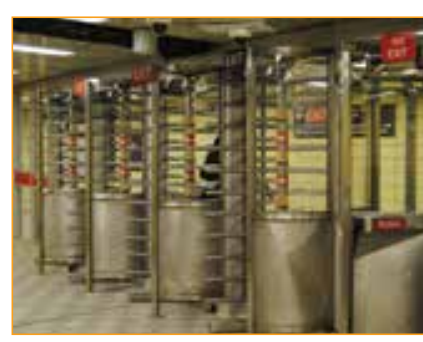

Exit signs have not been updated yet at various locations.

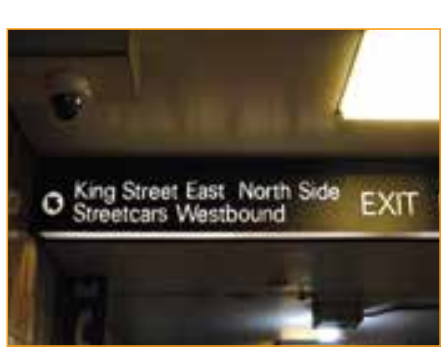
Signs are still under previous
standards and especially wordy 


\section{DESIGN SOLUTION A. \\ Education Campaign}

Description

This strategy aims to inform and

remind customers of proper conduct

in order to provide a comfortable and

enjoyable experience for everyone. An

etiquette campaign could be launched

across public transit on posters,

banners, advertisement space and

agency website.

Location

Chicago Transit Authority, Public

Transport Victoria, Tokyo Metro

Goal

Improve attitude towards public

transit and culture across the network.
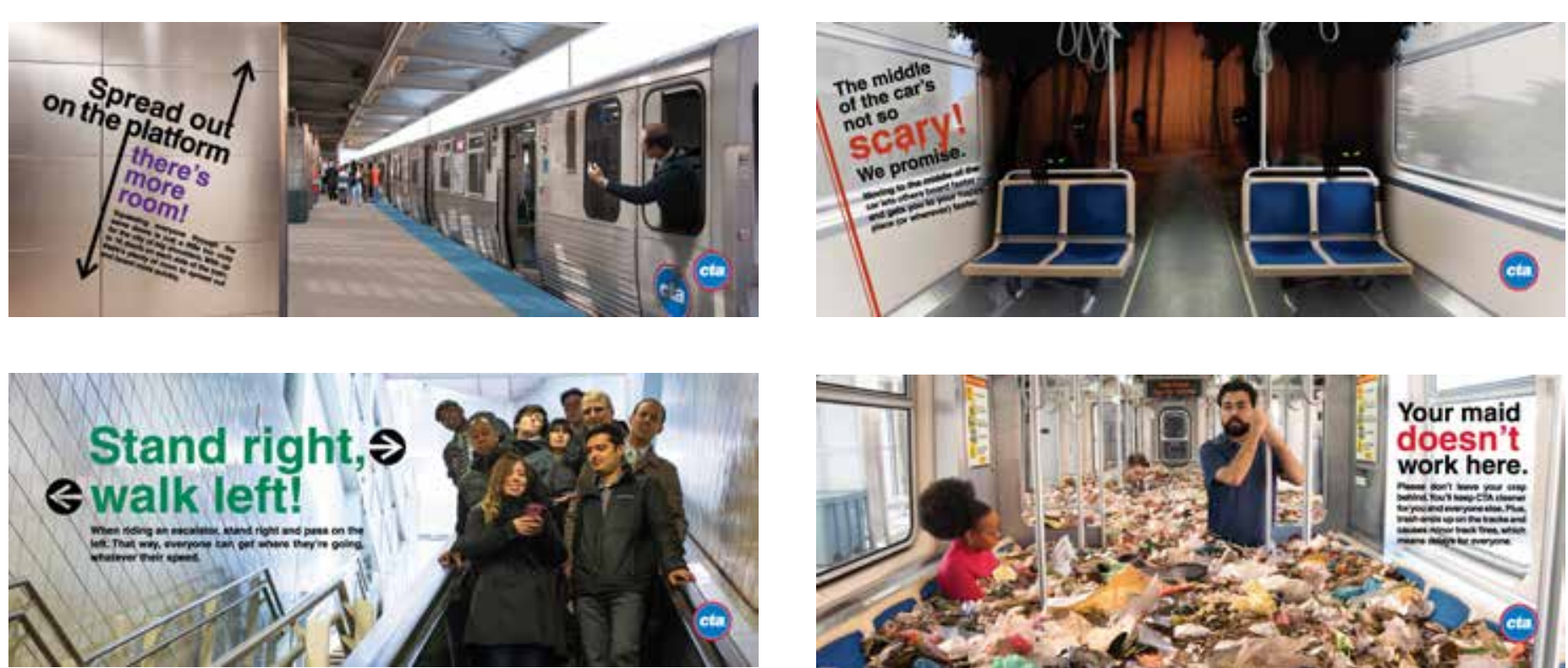

Chicago, Illinois

A courtesy campaign aimed to remind riders

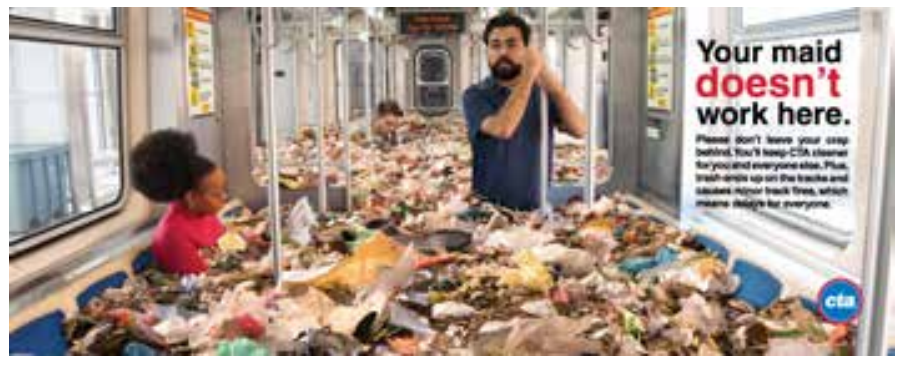

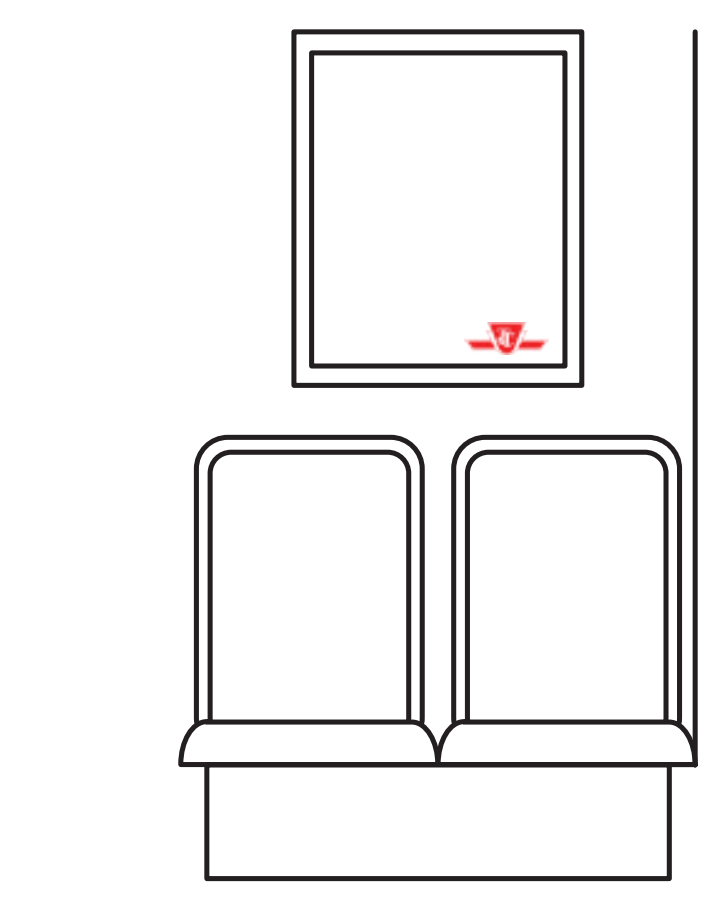

Rendering of a sign on a train that could host an education campaign.
Four of thirteen posters by the Chicago Transit Authority (CTA, 2017).

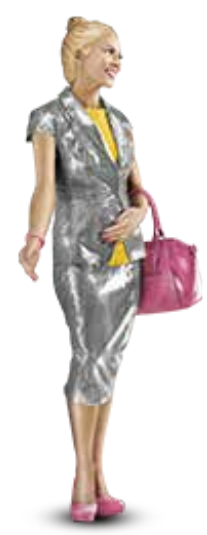

Tokyo, Japan posters every year. The campaigns are friendly and fun posters including animations mimicking riders

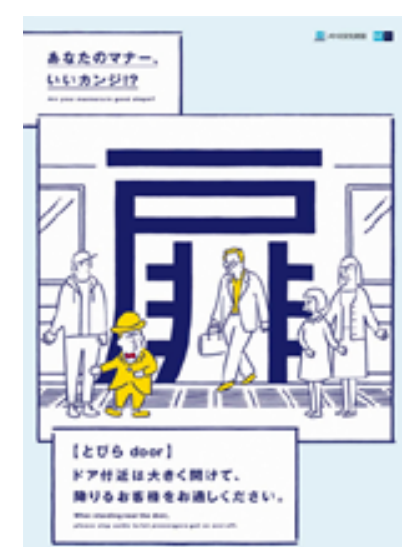

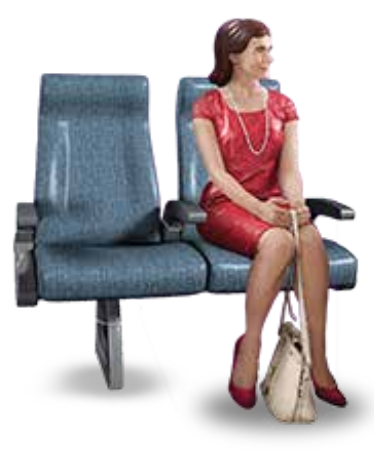

Victoria, Australia

Public Transport Victoria introduced the Model Commuters campaign to showcase good

commuters on transit including the 'floor bagger',
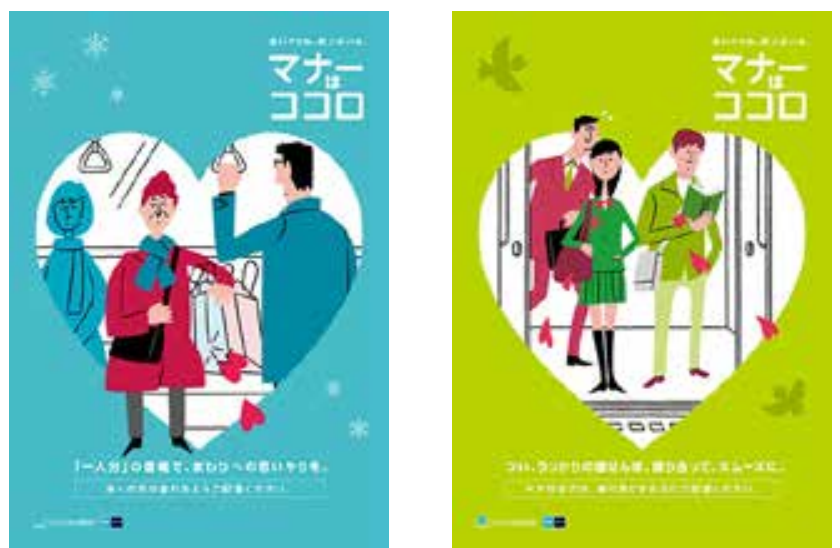

Since 1974, Tokyo Metro releases new etiquette
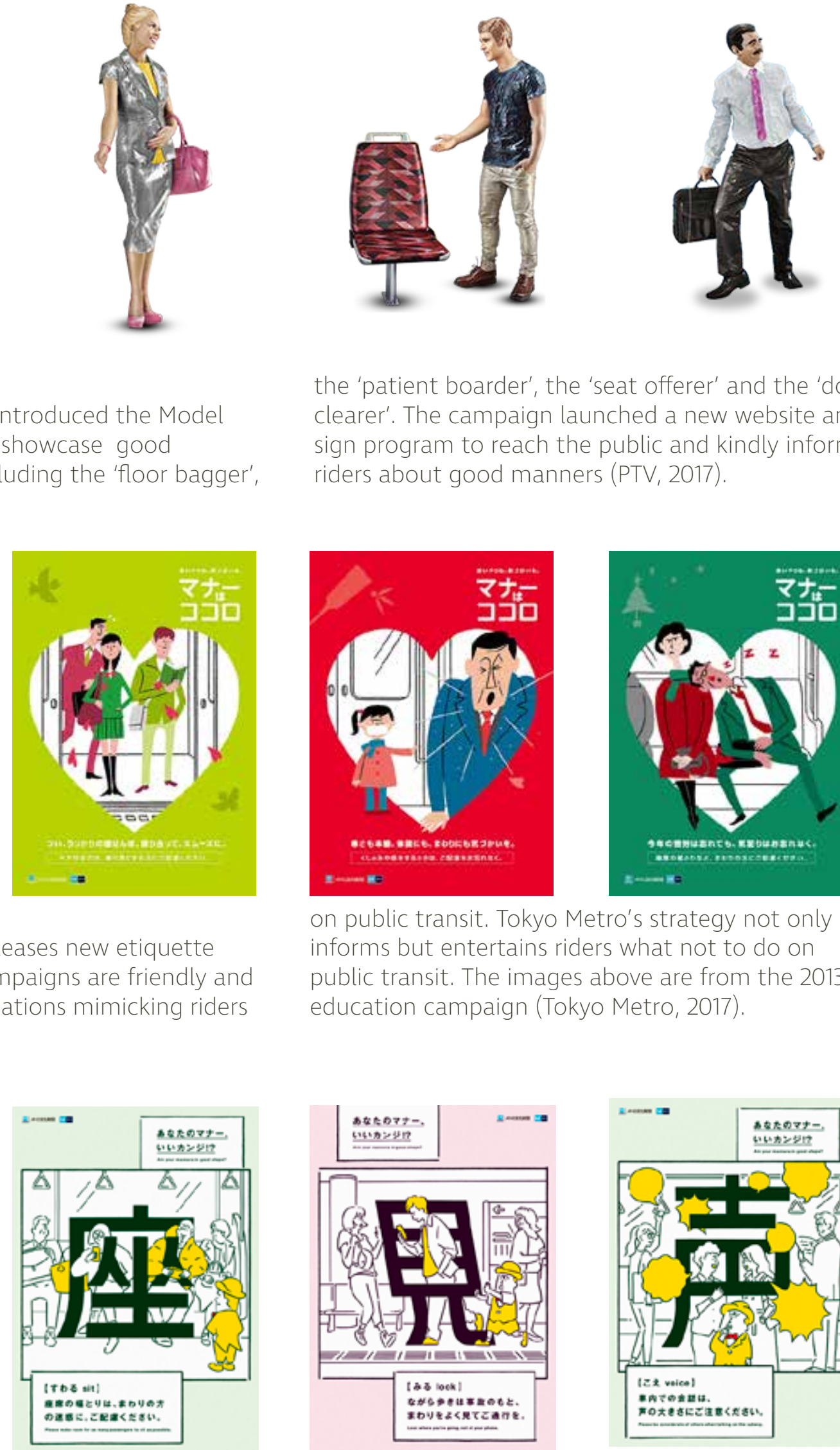

the 'patient boarder' the 'seat offerer' and the 'door clearer' The campaign launched a new website and sign program to reach the public and kindly inform riders about good manners (PTV, 2017).
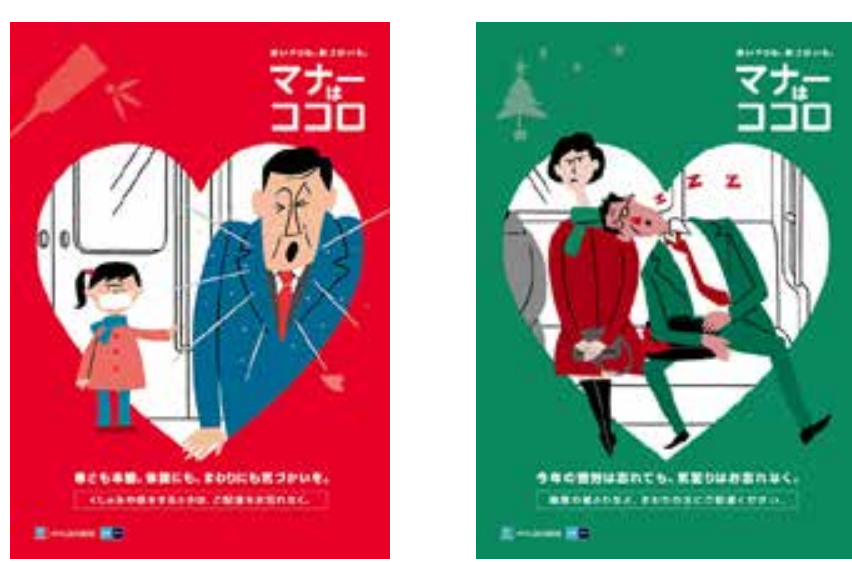

on public transit. Tokyo Metro's strategy not only informs but entertains riders what not to do on public transit. The images above are from the 2013 education campaign (Tokyo Metro, 2017).
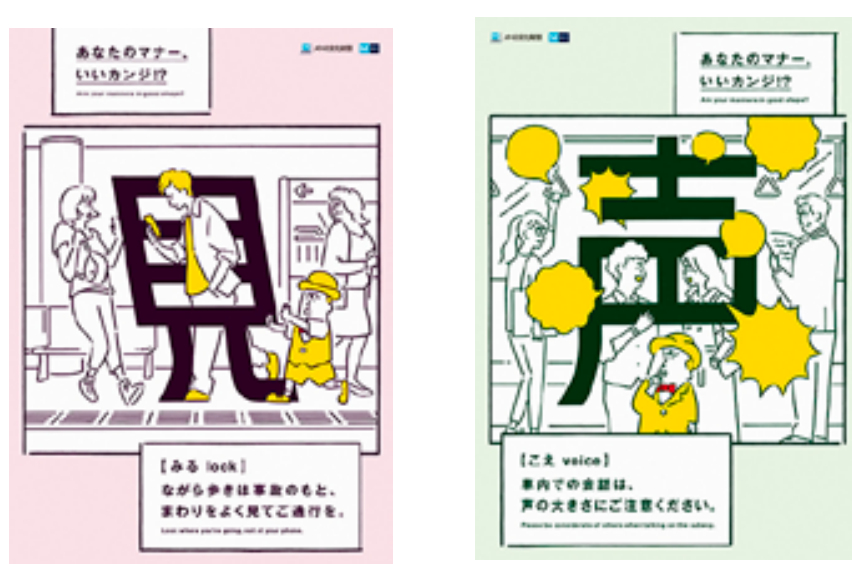

Tokyo, Japan

Pictures above are from Tokyo Metro's more recent poster series focused on behaviour considered inconsiderate to everyone else. Small captions

2016 etiquette campaign. Above are four of a twelve provide translation for English riders (Tokyo Metro, 2017). 


\section{DESIGN SOLUTION B.}

\section{Information Signs}

Description

Creative regulation, direction and

destination signs to help visitors know

where they are and where they need go

\section{Location}

London, New York City, Sydney and Shanghai

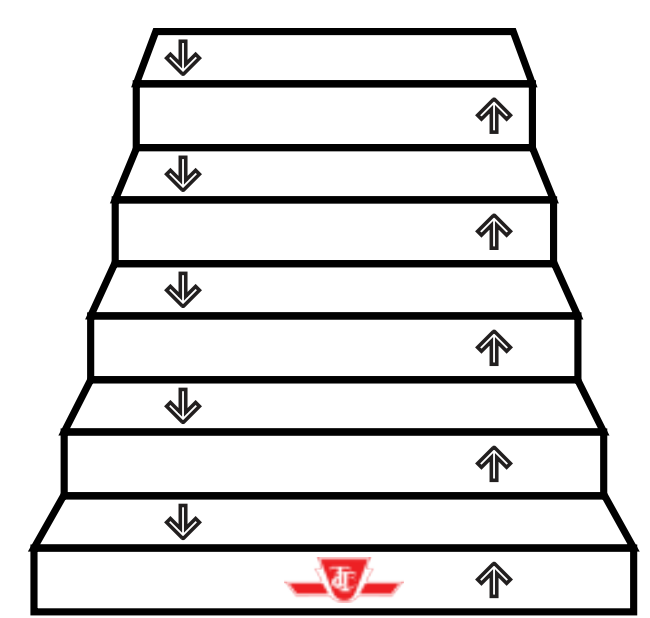
Rendering of stairs with arrows to
direct flow on the TTC

Improve wayfinding and flow in crowded areas including hallways,

underpasses, concourse and platforms.

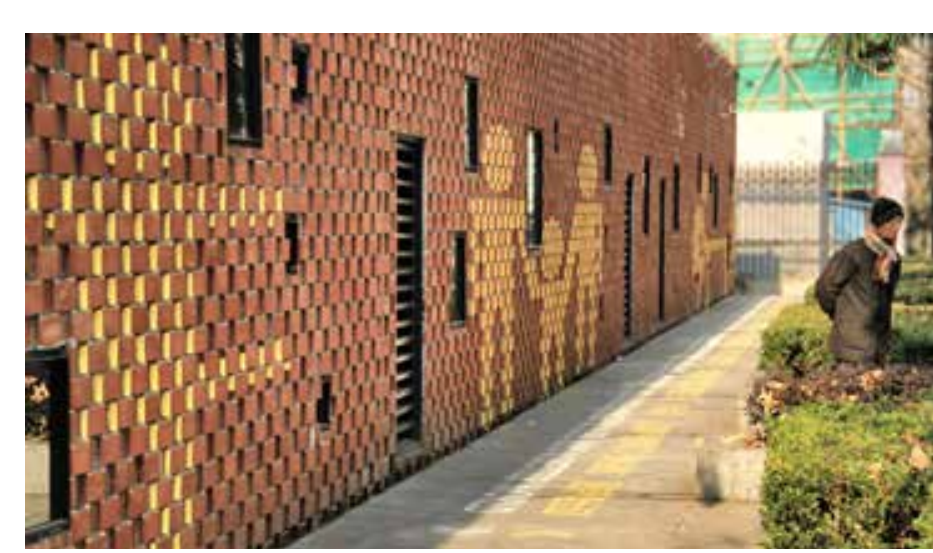
The designer used a fun and everyday language to remind drivers to continue or slow down. Arrows

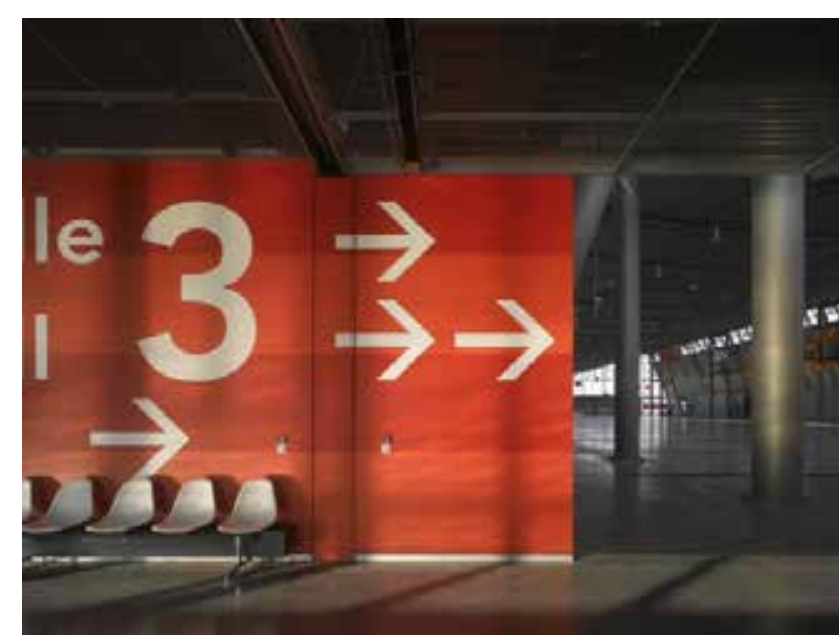

Barangaroo Carpark, Sydney The parking lot was and safe space. The designer used large scale icons to clearly indicate what parking level and where visitors can find the elevators.

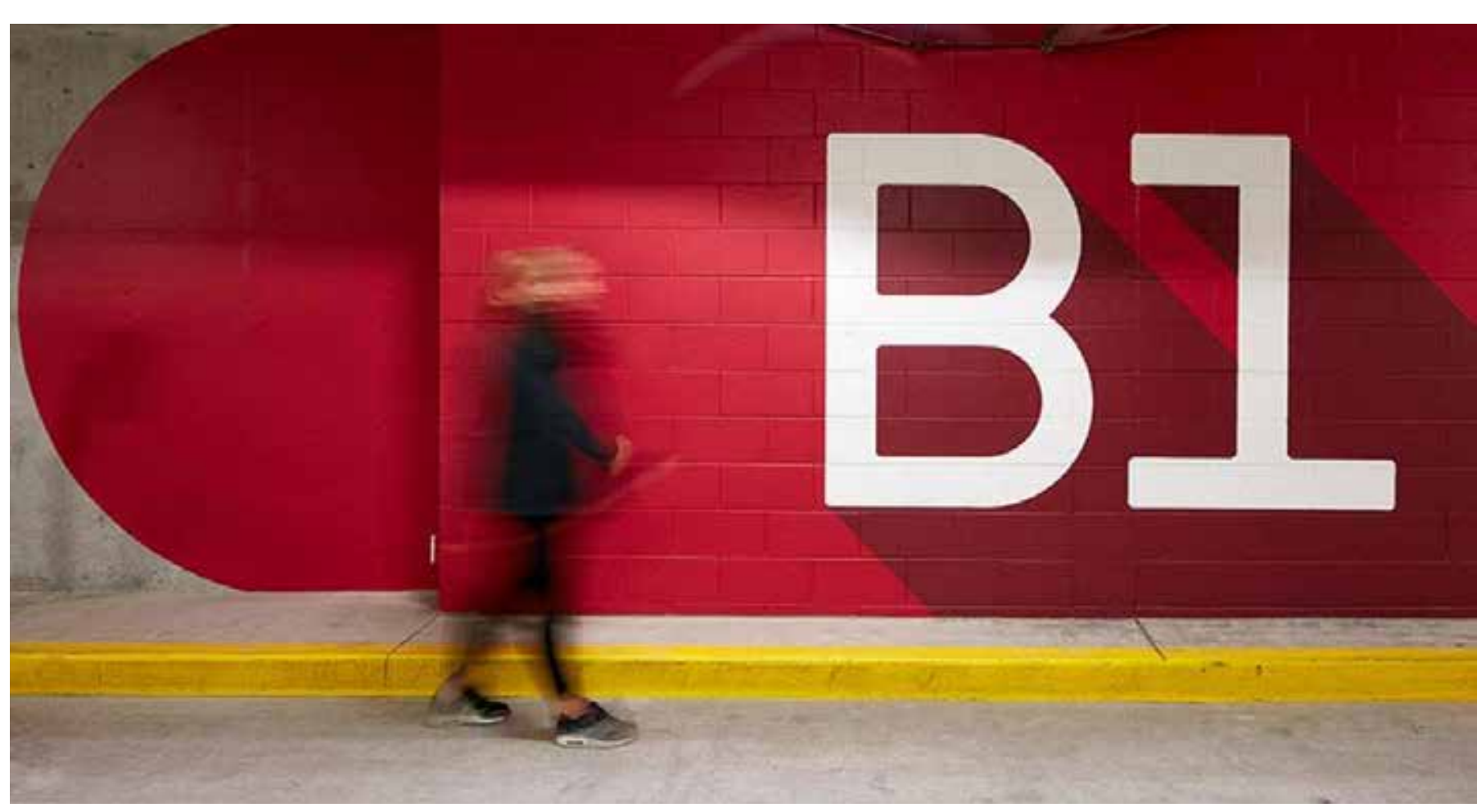

Cohen Bros. Realty parking lot, New York City were also painted to indicated correct direction.

Location: Tongii University Shanghai Simple graphics that reveal as pedestrians walk along the wall Different graphics can be seen walking left to right, and right to left activating the pathway. SEGD, 2016)

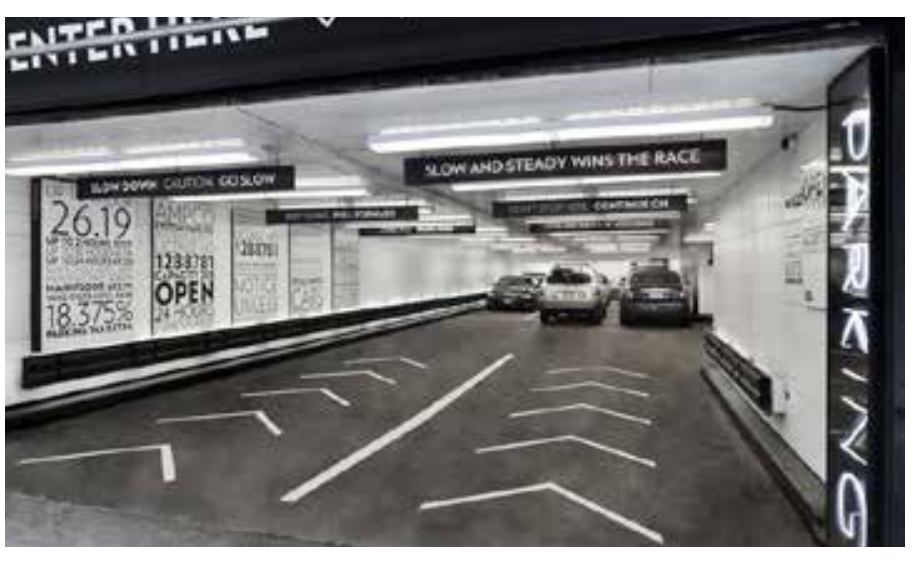

Ttuttgart Trade Fair, Stuttgart

Sthe exhibition centre used large scale and universal icons that ca be seen from great distances and help identify where to go. (Keane-Cowell, 2013)

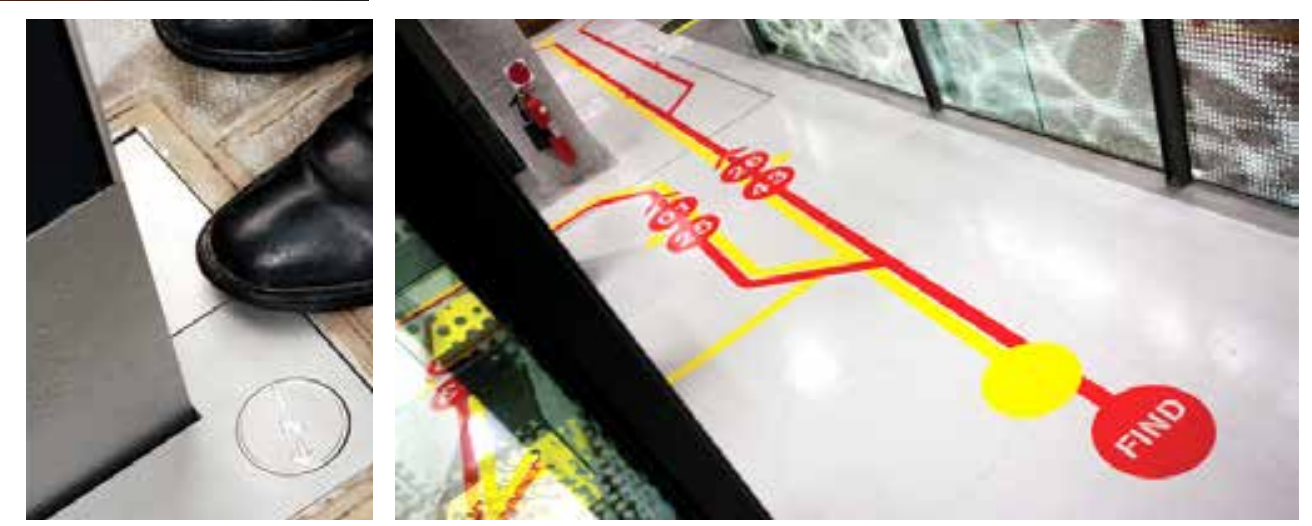

City of London The city adopted a wayfinding strategy including new maps and signs to help visitors and residents find their way. north arrows were engrave to gain sense of direction.
University of technology, Sydney The university used lines on the floor to help navigate students and promote safe workspace.
(Brand Culture, 2010) 


\section{DESIGN SOLUTION C.}

\section{Station Information}

Description

Detailed information about station

and nearby destinations to help

inform riders the best and timely

routes.

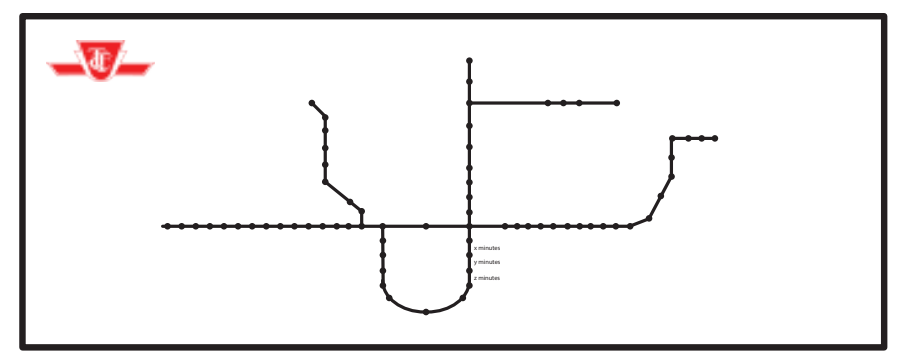

Location

Bonn, London and Tokyo.

Purpose

To improve wayfinding and flow for commuters.
Rendering of a banner on trains where more information about the network and stations could be provided including a transit map with walking time between stations.
Haus der Bildung Bonn, Bonn The municipal library produced simple floo plans to help visitors navigate specific genres and make the building legible.

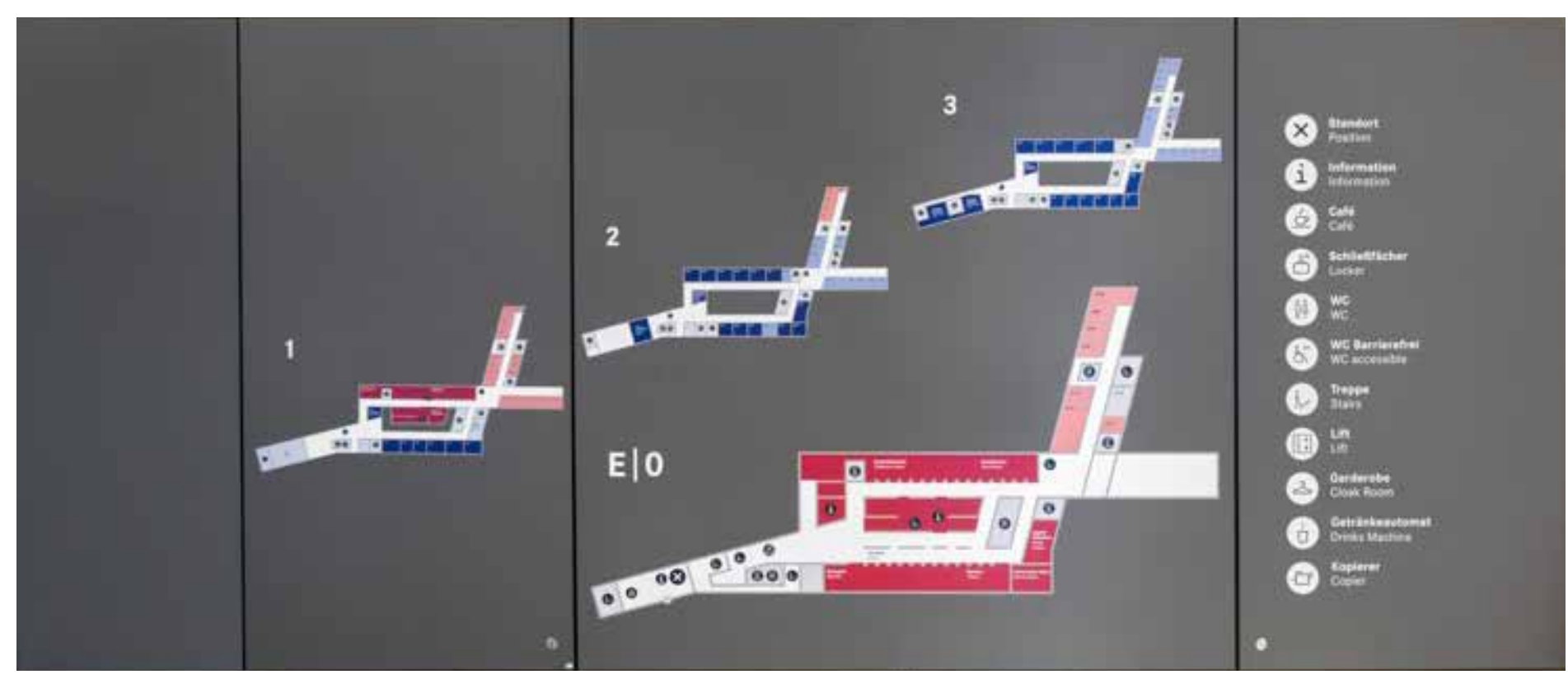

tso

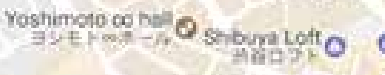

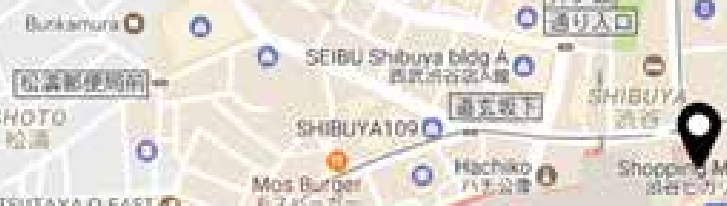

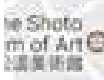
ค. 0:

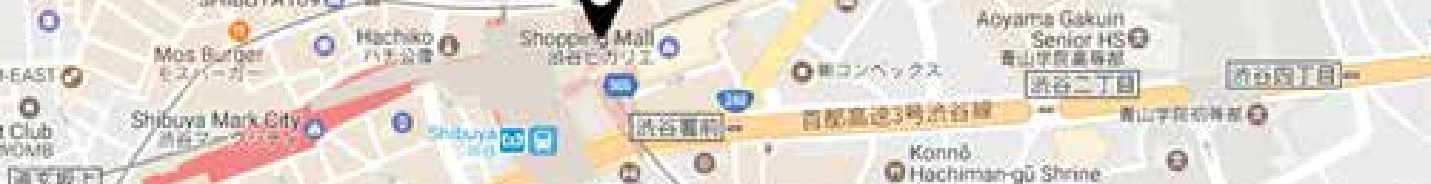

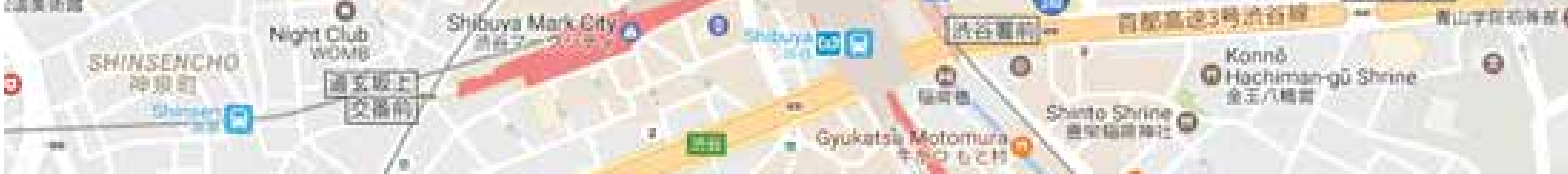

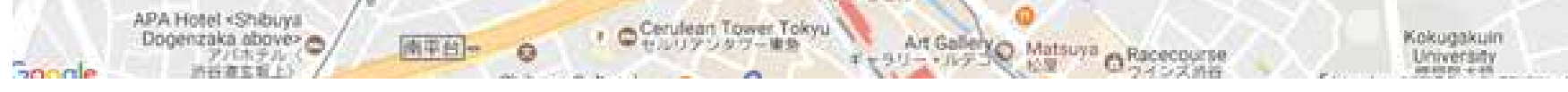

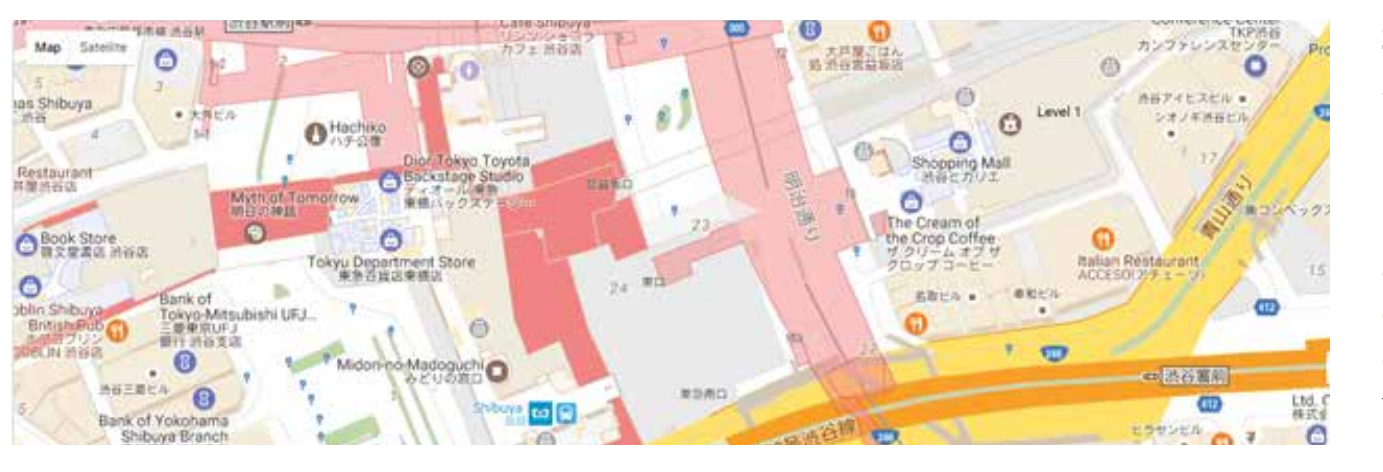

Shibuya Station, Tokyo Station layout with a maps are avatable to the pubs. Tokyo also to the ruc. Tokyo also provid cach station exit allowing comnuters to navigateto Tokyo Metro, 2017)

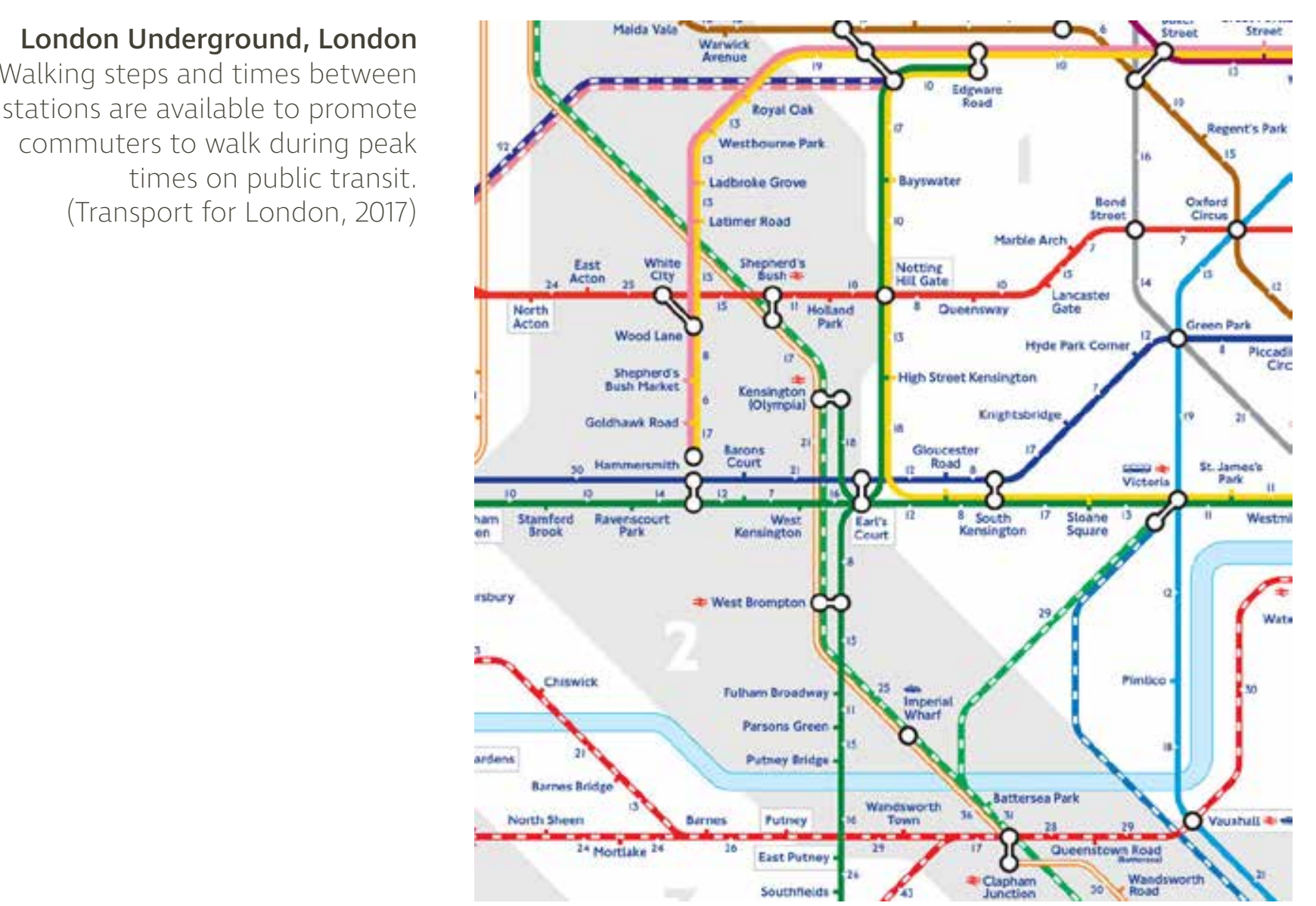




\section{DESIGN SOLUTION D.}

Multiple Languages

Description

Making complicated and detailed

information available in multiple

languages to help navigate

complicated environments.

Location

Brisbane, Shanghai

\begin{tabular}{|c|c|}
\hline ००० & 一ロ \\
\hline \multirow{4}{*}{$\begin{array}{c}\text { Welcome } \\
\text { Bienvenue } \\
\text { 歡迎 } \\
\text { स्वागत }\end{array}$} & ようこそ \\
\hline & 환영합니다 \\
\hline & الهسو \\
\hline & الـهأ \\
\hline & $-\sqrt{-1}$ \\
\hline
\end{tabular}

Purpose

Improve wayfinding and culture

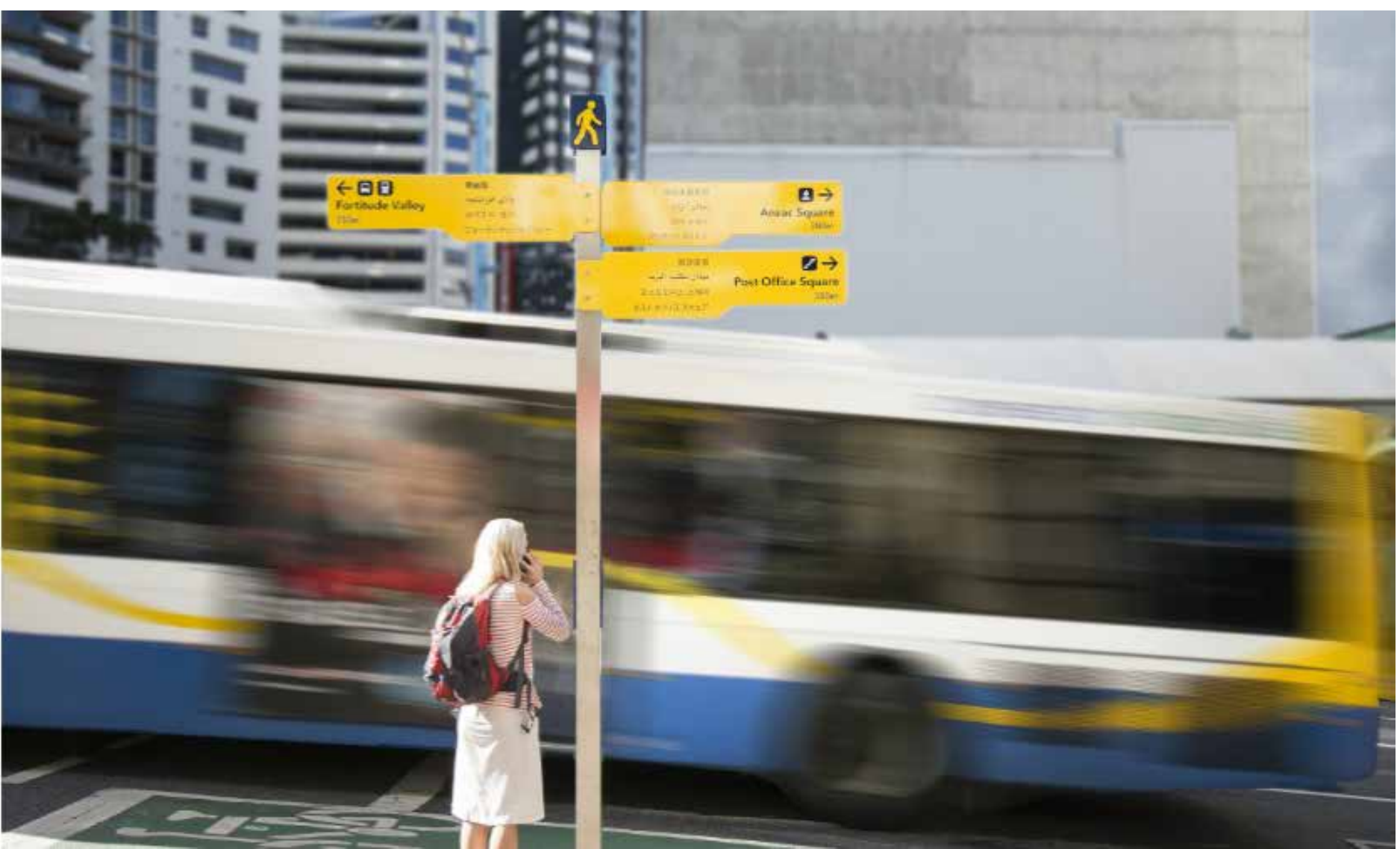

The following transportation agency provide transit information in multiple languages:

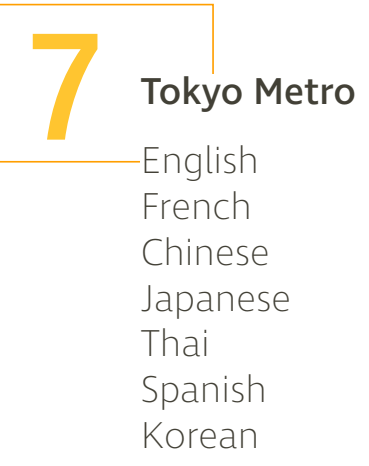

Arabic

Amenian

Azerbaija

Basque

Belarusian

Bulgaria

Croatian

Czech
Danish
Dutch
Estonian
Filipino
Finnish
French
Galician
Georgian
Greek
Haitian Creole

Hebrew

Hindi

Hungarian

Hungarian
Icelandic

Indonesian

Irish

(1) London Underground

Arabic Hind

Bengali

Chinese

German

Spanish

French

Greek

Gujarati

Macedonian Slovenian

Malay Spanish

Maltese Swahili

Norwegian Swedish

Persian

Polish

Portuguese Ukrainia

talian Portuguese

Japanese

Korean

Latvian

Lithuanian

Romanian

Russian

Serbian

Slovak
Hindi
Italiano

Polski

Portugues

Punjabi

Tamil

Turkish

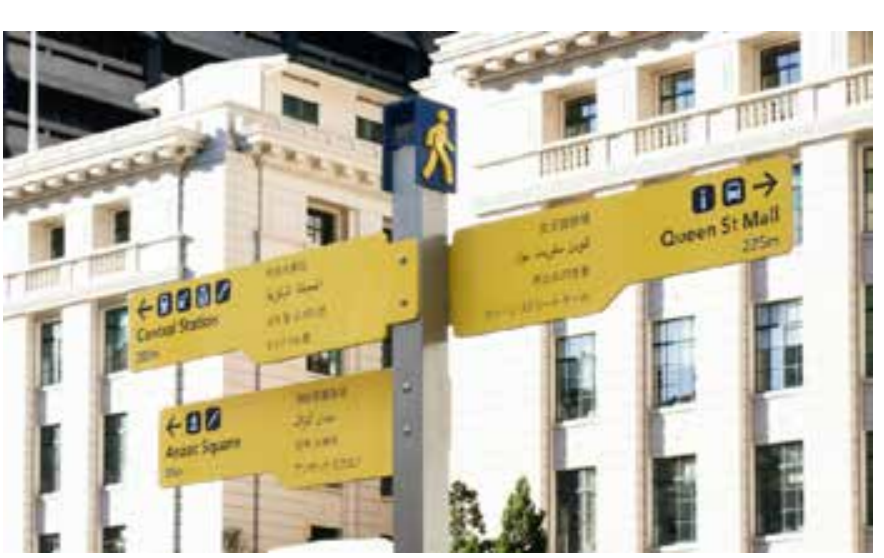

Brisbane, Australia

to welcome international visitors and

residents, the city designed it pedestrian signage

to accommodate up to five languages including

Korean, Japanese, Traditional Chinese and Arabic at

33 location in the city centre.

Tongji University, Shanghai Vietnamese Welsh Yidish space for Chinese characters and English translation.

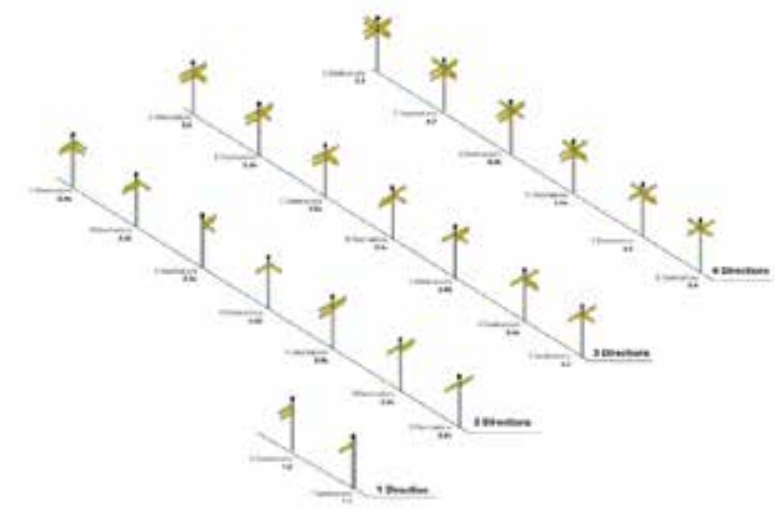




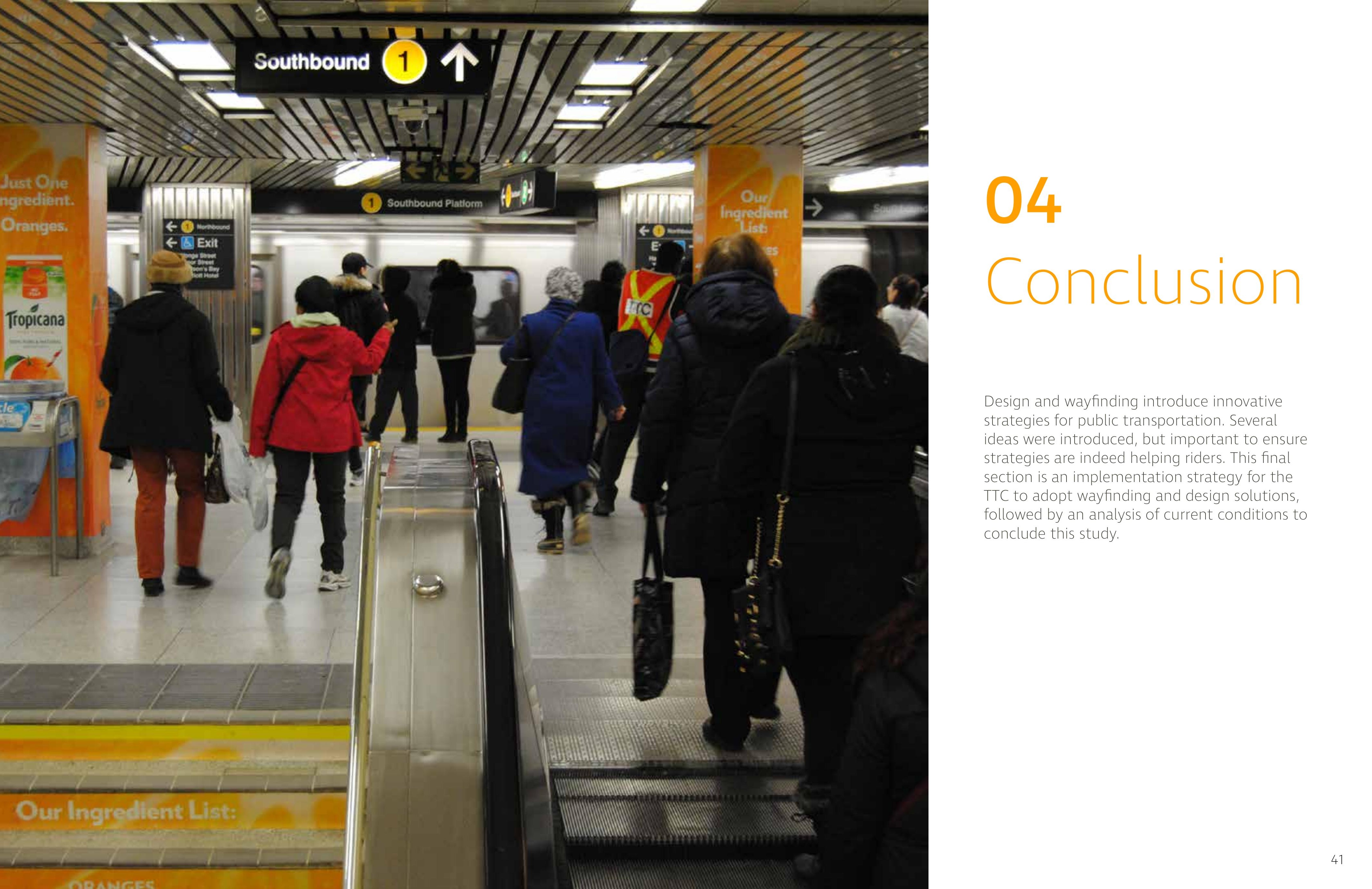




\subsection{Implementation Strategies}

\subsection{Current Conditions}

This project explores a variety of wayfinding strategies that could be adopted by the TTC to improve attitude, flow, culture and wayfinding processes. Some solutions received great response and have been awarded for its creativity and innovation in different locations. The success of these designs, however, may not carry out the same results within Toronto's public transit. At the end of the day, strategies should help wayfinding and flow between connections, and hopefully create a more comfortable and enjoyable transit experience.

These proposed strategies can significantly impact the users, thus it is important to

involve commuters in planning for wayfinding (Gibson, 2009). Conversations with the riders should be carried out throughout the process to gain insight on their experience. Engaging with riders at central locations and at various times of the day and week would allow planners to gain better understanding of the wayfinding process. Riders should also be involved in testing solutions to observe the public's response and the viability (Gibson, 2009).

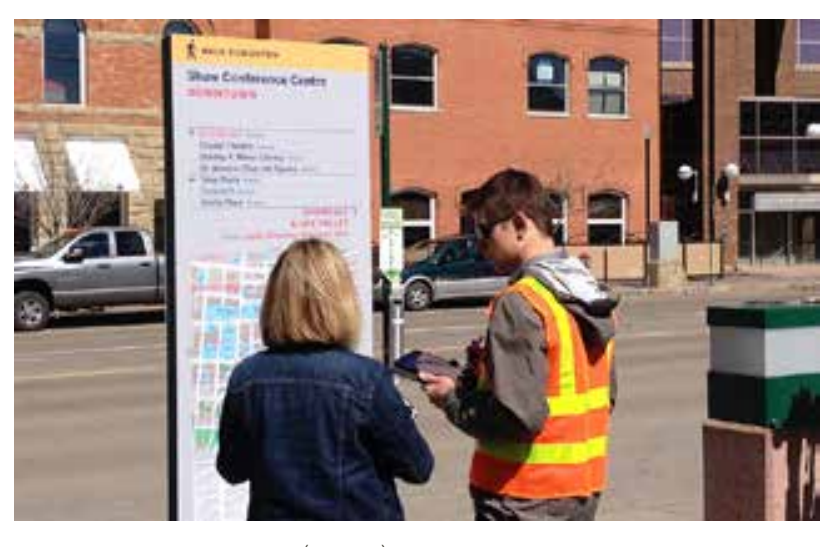

City of Hamilton (2017) conducted a pilot sign survey to gain feedback from the public of the new city wayfinding signs.

Pilot studies are commonly used to test the content of wayfinding strategies. City of Edmonton, Metrolinx and the TTC evaluated new wayfinding standard at different locations to observe the reception. Pilot studies allow designers to talk to riders directly and gain feedback on new ideas. This method allows the designer to gauge the effectiveness of the wayfinding programs. In all, important to make sure new strategies are sensible within the surrounding context, and that TTC riders find them helpful. Pilot studies should aim for central locations and at various times of the day in order to reach the greater public. New design and wayfinding strategies should make the commute even more effortless and simple to navigate a complex environment.
In summary, the TTC has introduced some new technology and strategies to address challenges on public transit. The installation of the new PRESTO system certainly moves people faster with just tap to pay your fare. The Art for Commuters is also an excellent program connecting with local artists and enhancing the transit experience. Above all, the TTC developed a new design standard for wayfinding and signage, in 2014. A specific set of colours, font, pictograms, arrows and text were designed to apply across the network. In the Corporate Plan, the TTC aimed to have wayfinding updated by the year end of 2017. With less than a year left, the TTC have yet to update several signs across the network.

However, signs under previous standards that yet need to be replaced pose challenges for commuters. Long directional messages on

signs require a few seconds to read as opposed to an arrow that requires just a glance. These wordy signs are still seen in stations that cater to a large volume of traffic on a daily basis. Signs hanging diagonally not only make it hard to read but also make public transit appear neglected and less attractive. Cluster of information about the service and network is also placed at non-strategic locations. These eyesores prevent public transit to become a modern and desirable mean of transportation. In addition, wayfinding, attitude, flow and culture as result suffer on public transit.
Nonetheless, the TTC did significant and attractive transformation in new stations including Union Station. Consistent and new sets of signs were integrated with the renovation. Information about the local area including the $\mathrm{CN}$ tower, for example, is clearly identified at the entrance of the station. Wayfinding at Union station set a benchmark that the TTC should aim for every station. The TTC should be encouraged to continue implementing programs such as these to improve riders' experiences.

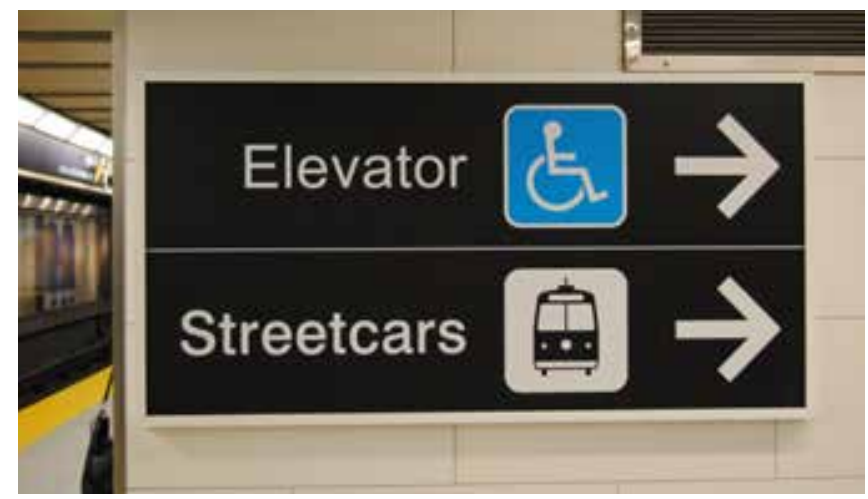

New wayfinding signs in the newly renovated Union station downtown Toronto. 


\subsection{New Strategies}

Toronto's downtown core is experiencing tremendous population growth and development. These trending pulses are adding stress to the TTC's already crowded and underinvested transit system. However, this study aimed to introduce new design and wayfinding strategies that would not require changing the level of service or station architecture. The approach of this study has

centred on providing a comfortable and enjoyable commute by addressing wayfinding, flow, attitude and culture. Creative and colourful strategies present the opportunity to integrate art and culture providing a more interesting experience rather than just a mean to reach a destination.

\section{HANDRAIL}

Recommendation also included more information about the network and the station to help

customers easily navigate convoluted spaces. This study has demonstrated the immense potential for wayfinding solutions to improve overall transit for riders of the TTC, thus enabling public transit to become an attractive mode of transportation in the face of mounting competition. By making directions and circulation easy, connections areas no longer need to be an inconvenience. Instead, public transit can become simple, comfortable, and an enjoyable commute. 


\section{Appendix A}

Property Permit (to take photographs on TTC property)

CONDITIONS FOR FILMING/PHOTOGRAPHING UNDER A PROPERTY PERMIT

$$
\text { ON TTC PROPERTY }
$$

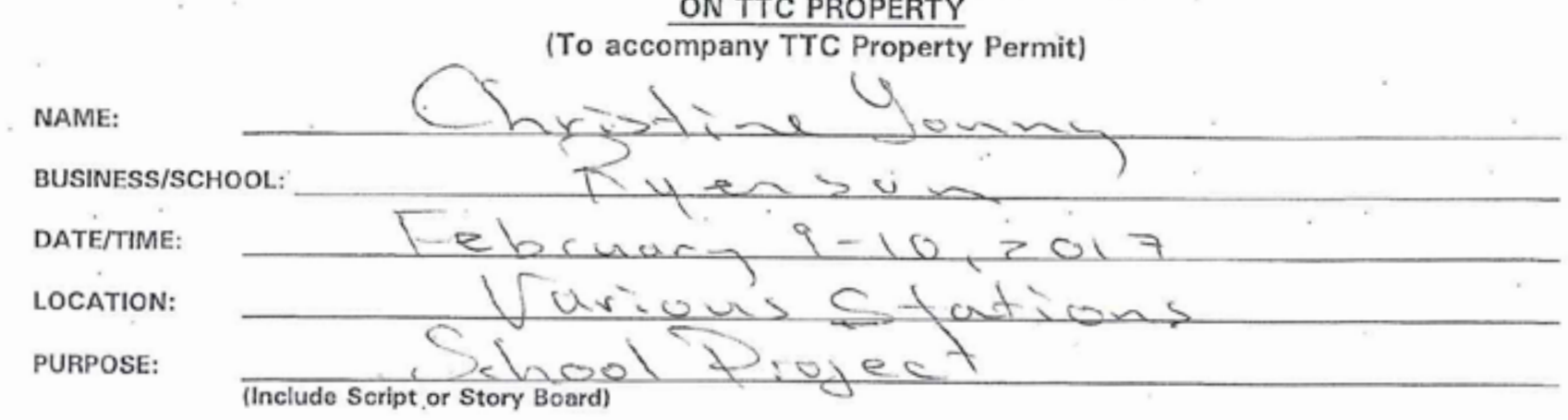
1. This permit allows access to the premises designated ONLY. It is not a parking permit and is not to be used for parking
on TTC property or used for tree transportation. You will be required to pay a fare to enter subway stations or vehicles.

2. TTC may revoke this permit at anytime.

3. This permit is not transferable. It may be used only by the person named hereon.

4. Permit is not valid until the particulars are entered on the front and the Permit is signed in the spaces provided.

5. Permit must be returned to the TTC when holder is no longer qualified to use it.

6. Permit must be shown to any TTC employee if requested. 7. No more than FOUR people are allowed to participate in the film/photography work, between the hours of 10 am to 3
$\mathrm{pm}$ and $7 \mathrm{pm}$ to $1: 30$ am, without the supervision of the TTC Filming Specialist.

8. Absolutely NO camera flashes or artificial lighting is to be directed toward oncoming trains.

9. Absolutely NO interviews or shots of TTC customers or employees will be conductod, without written consent of the Marketing and Corporate Communications departments

10. No filming/photographing will be allowed where a person is standing within the yellow plattorm edge marker tiles. All

11. No equipment shell be placed on or close to the edge of the yellow platform edge marker tiles or interfere with

12. Absolutely NO entry or filming/photographing is allowed at track level.

13. Absolutely NO entry onto subway trains is permitted unless accompanied by TTC Fillming Specialist or Transportation

14. Absolutely NO use of ladders, large equipment or props without supervision of TTC Filming Specialist.

15. The direction of any TTC employee MUST be followed immediately at all times.

16. Film or photos of any safety/security incident/accident must be surrendered to the TTC/Toronto Police Services and cannot be used without the written consent of the TTC.

I have read, understood and agree to these conditions:

\section{Appendix B}

Certificate of Insurance

CURIE

CANADIAN UNIVERSITIES RECIPROCAL INSURANCE EXCHANGE

CERTIFICATE OF INSURANCE

\section{INSURED}

Ryerson University
350 Victoria Street
Toronto ON

Contact: Carrol Scanlan

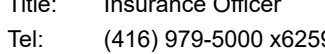

Email: cscanlan@ryerson.ca

Reference

Nature of Operations:
Student filming on TTC property all year. - DATES: On-going

Certificate №: $\quad 63392$

Issue Date: 2017-01-01

This is to confirm that insurance as described herein is in full force and effect on behalf of the Named Insured and as more fully described in said policies and any

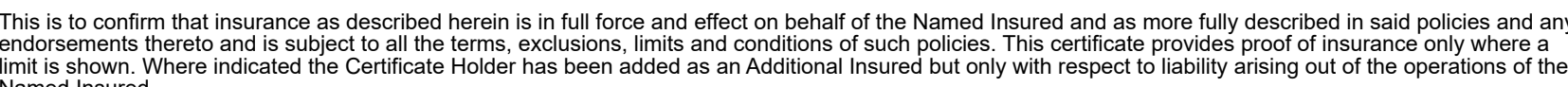

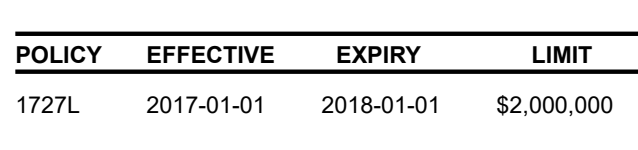

COMPREHENSIVE GENERAL LIABILITY

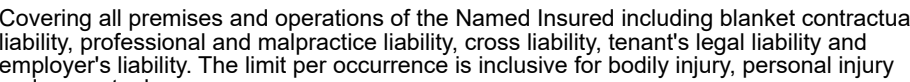

$\square$ Cerificicate Holder as Additional Insured

EDUCATIONAL INSTITUTIONS ERRORS AND OMISSION

Covering Errors and Omissions Liability and Professional Liability of the Named Insured
On a claims made basis.

PROPERTY

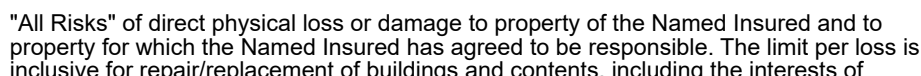

nclusive for repairr replacement of buildings and contents, including the interests of

$\square$ certificate Holder as Additional Insured/Loss Payee (ATMA)

EXCESS PROPERTY

"All Risks" of direct physical loss or damage to property of the Named Insured and to
property for which the Named Insured has agreed to be responsible. Thu limit per loss is

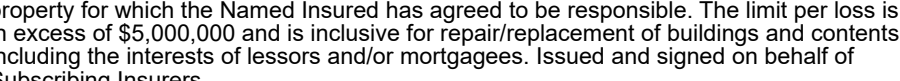

CUR

$$
\text { dai bagt }
$$




\section{Sources}

Arthur, P. \& Passini, R. (1992). Wayfinding: People Signs, and Architecture. Oakville, ON: McGraw Ryerson Limited.

Beirão, G., \& Sarsfield Cabral, J.A. (2007). Understanding attitudes towards public transport and private car: A qualitative study. Transportation Policy, 14, 478-489.

Brand Culture. (2010). Graphic Ambient. Retrieved from

http://graphicambient.com/2011/11/27/university-of-technology-sydney-australia/

Brown, S. (n.d). Barangaroo Carpark Wayfinding.

Retrieved from http://there.com.au/work/BarangarooCarpark

Chicago Transit Authority. (2007). Retrieved from http://www.transitchicago.com/

Chicago Transit Authority. (n.d.). CTA Public Art.

City of Edmonton. (2017). Navigating a Changing Downtown

Retrieved from https://www.edmonton.ca/projects_plans/design_studies/wayfinding.aspx

City of Toronto. (2016). Proposals Report: TOcore Planning Downtown.

Denis, J., \& Pontille, D. (2015). Material ordering and the care of things. Science, Technology, \& Human Values, 40(3), 338-367. doi:10.1177/0162243914553129

Farr, A. C., Kleinschmidt, T., Johnson, S., Yarlagadda, Prasad K. D. V, \& Mengersen, K. (2014). Investigating effective wayfinding in airports: A Bayesian network approach. Transport, 29(1), 90-99

Frisken, F. and Soberman, R. M. (2010). Residential and Civil Construction Alliance of Ontario, \& Risk Analytica. (2010). Delivering transit service in the GTHA: Where we are is not where we want to end up RiskAnalytica.

Gibson, D. (2009). The Wayfinding Handbook: Information Design for Public Places. New York NY: Princeton Architectural Press.

Guo, Z. (2009). Does the pedestrian environment affect the utility of walking? A case of path choice in downtown Boston. Transportation Research Part D, 14(5), 343-352.

Guo, Z. (2011). Mind the map! the impact of transit maps on path choice in public transit. Transportation Research Part A, 45(7), 625-639.

Guo, Z., \& Wilson, N. H. M. (2011). Assessing the cost of transfer inconvenience in public transport systems: A case study of the London underground. Transportation Research Part A, 45(2), 91-104.
Keane-Cowell, S. (2013). Signs of the Times. Retrieved from

https:/ www architonic com/en/story/simon-keane-cowell-signs-of-the-times/7000779

Kepaptsoglou, K., Karlaftis, M. G. \& Gkountis, J. (2013). A fuzzy AHP model for assessing the condition of metro stations. KSCE Journal of Civil Engineering, 17(5), 1109-1116. doi:10.1007/

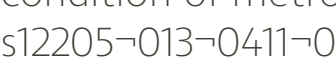

Li, P., Hibino, H., Koyama, S., \& Zheng, M. (2012). Tailoring Map Design Based on Map-Reading and Way-Finding Behaviour in Subway Stations. Procedia - Social and Behavioral Sciences, 42, 466-476.

Metrolinx. (2008). The Big Move: Transforming Transportation in the Greater Toronto Hamilton Area.

Metropolitan Transportation Authority. (2017). Retrieved from http://www.mta.info/

National Ballet of Canada. (2017). We Move You. Retrieved from https://national.ballet.ca/Explore/We-Move-You

Neuman, L. W. (2006). Social Research Methods: Qualitative and Quantitative Approaches (6th ed.). Boston, MA: Pearson Education, Inc.

Ostler, T. (2014). Downtown Toronto: Trends, Issues, Intensification. City of Toronto.

Popuri, Y., Proussaloglou, K., Ayvalik, C., Koppelman, F., \& Lee, A. (2011). Importance of traveler attitudes in the choice of public transportation to work: Findings from the regional transportation authority attitudinal survey. Transportation, 38(4), 643-661. doi:10.1007/s11116 011-9336-y

Public Transport Victoria. (2017). https://www.ptv.vic.gov.au/

Raveau, S., Guo, Z., Muñoz, J. C., \& Wilson, N. H. M. (2014). A Behavioural Comparison of Route Choice on Metro Networks: Time, Transfers, Crowding, Topology and SocioDemographics. Transportation Research Part A: Policy and Practice, 66, 185-195.

Reeve, B. (2017). TTC selling Honest Ed's Signs from Bathurst Station. Retrieved from http:/ www.blogto com/city/2017/03/ttc-selling-honest-eds-signs-bathurst-station/

Rüetschi, U. \& Timpf, S. (2005). Modelling Wayfinding in Public Transport: Network Space and Scene Space. Springer Berlin Heidelberg,3343, 24-41.

Society for Experiential Graphic Design. (2010). Awards. Retrieved from https://segd.org/global-design-awards/2010-awards

Society for Experiential Graphic Design. (2011). Awards. Retrieved from https://segd.org/global-design-awards/2011-awards

Society for Experiential Graphic Design. (2014). Awards. Retrieved from 
Society for Experiential Graphic Design. (2016). Awards. Retrieved from

https://segd.org/global-design-awards/2016-awards

Tokyo Metro. (2017). Retrieve from http://www.tokyometro.jp/en/index.html

Toronto Transit Commission (2013). Five-Year Corporate Plan 2013-2017.

Toronto Transit Commission. (2015). 2015 Customer Charter. Retrieved from https://www.ttc. ca/Customer_Service/Customer_Charter/2015_charter.jsp

Toronto Transit Commission. (2016). 2016 Customer Charter. Retrieve from https://www.ttc. ca/Customer_Service/Customer_Charter/2016_Charter.jsp

Transport for London. (2017). Retrieved from https://tfl.gov.uk/

Society for Experiential Graphic Design. (2017). A Multidisciplinary Community Creating Experiences that Connect People to Place. Retrieved from https://segd.org/

Transport for London. (2017). Retrieved from https://tfl.gov.uk/

Yuval, H. \& Ranjitkar, P. (2012). Modeling Public-Transit Connectivity with Spatial-of-Transfer Measurements. Journal of Transport Geography, 2, 137-147.

Zerdoun, Catherine. (2016). Under Ground Subways and Metros of the World. Richmond Hill, On: Firefly Books. 
